\title{
Competitive Bidding for a Long-Term Electricity Distribution Contract
}

\author{
STEPHEN C LITTLECHILD* \\ Honorary Professor, University of Birmingham Business School \\ Principal Research Fellow, Judge Institute of Management Studies, University of Cambridge
}

\begin{abstract}
Demsetz (1968) and Posner (1972) suggested competitive bidding as an alternative to natural monopoly regulation. Williamson (1976) and Goldberg (1976) argued that the problems of natural monopoly regulation are inherent in long-term investment under uncertainty. Long- and short-term franchising contracts may be more problematic than regulation. This paper reviews the literature and UK experience. It examines London Underground's recent long-term (thirty-year) contract for its electricity distribution network. This has avoided the Oakland CATV problems described by Williamson, but involves considerable resources to monitor. Competitive contracting seems feasible and advantageous versus public provision. Its merits versus utility regulation warrant further consideration.
\end{abstract}

\section{Introduction: Competitive bidding and utility regulation in the economic literature}

During the 1960s there was active discussion of the alleged inadequacies of US public utility regulation. There were concerns that it was ineffective or had undesirable side effects. For example, rate of return regulation provided inadequate incentive to reduce operating costs and could encourage over-investment in capacity (e.g. Averch and Johnson, 1962, and many others).

Demsetz (1968) invoked the analogy of competition for the market where competition within the market was not possible ${ }^{1}$. The bulk of his paper was devoted to disputing the proposition that natural monopoly would lead to a monopoly price. Subsequent critics do not seem to have challenged this part of his argument, though Stigler noted that allowance must be made for transactions costs ${ }^{2}$.

\footnotetext{
* Mailing address: White House, The Green, Tanworth-in-Arden, Solihull, W Mids. B94 5AL, England, U.K. E-mail address: sclittlechild@tanworth.mercianet.co.uk I am grateful to Seeboard plc for supporting the initial research, and to Brian Gray, Managing Director of SPL, and Ian Buchanan, Energy Contracts Manager of LUL, for explaining the SPL/LUL contract discussed in this paper. I have benefited from helpful comments by Ronald Coase, Harold Demsetz, Edward Humpherson, Mary Shirley, Oliver Williamson, the editors of this journal and a referee. Responsibility for errors is mine alone.

${ }^{1}$ The original idea can be traced back to Chadwick (1859) though Foster (1992: 39 at fn. 36) has suggested that a Liberal MP James Morrison had the essential idea before Chadwick.

2 "The role of low or zero transactions costs in dealing with customers deserves emphasis. ... If a potential rival must resort to the more costly procedure of canvassing all possible customers and arranging contracts, he will not be tempted to enter unless the price exceeds the monopolist's costs by the potential rival's additional
} 
Demsetz was in turn led to question the justification for utility regulation, and noted that an alternative could be bidding to supply the market at lowest price ${ }^{3}$. In this way the restraint of the market would be substituted for that of the regulatory commission. In his view, "the rivalry of the open market place disciplines more effectively than do the regulatory processes of the commission."

Competitive bidding seems to have been endorsed by Stigler, who illustrated it using electricity generation and distribution ${ }^{4}$. He also remarked on the possibility of its use by trade associations ${ }^{5}$. Posner advocated franchise bidding in the context of regulation of the cable television industry. ${ }^{6}$

These authors to some extent acknowledged, but did not examine in any detail, the practical implications of bidding solutions compared to other approaches. For example, Demsetz noted the need for a contract to consider how best to cope with uncertainty, which would have implications for duration and price. He did not seek to evaluate the various possibilities $^{7}$ Although examining a particular sector and making policy recommendations, Posner (1972:98) said that "to expound the details of particular regulations and proposals ... would serve only to obscure the basic issues". He acknowledged that all options had difficulties ${ }^{8}$. However, some of the remarks in these papers might imply that franchise bidding is likely to have lower transactions and other costs than alternative approaches. ${ }^{9}$

costs of transactions." Stigler (1968: 19) The references and experience discussed in the present paper no doubt have implications for the size and nature of such costs and price.

${ }^{3}$ Demsetz (1968: 63) actually mentioned two possible arrangements. "A franchise system that awarded the franchise [to serve a particular market area] to that company which seemed to offer the best price-quality package would be one that allowed market competition between bidding rivals to determine that package.... An alternative arrangement would be public ownership of the distribution system.... The system could then be installed by the bidder offering to do the specified job at the lowest price. Again the market is substituted for the regulatory commission."

4 "Natural monopolies are often regulated by the state. We note that customers can auction off the rights to sell electricity, using the state as the instrument to conduct the auction ... . The auction now consists of a promise to sell cheaply;" (Stigler, 1968: 19).

5 "Even if the services [provided by a trade association] ... are 'natural monopolies', ... a rival association can still bid away the members of the group with a lower price.” (Stigler, 1974: 360). He footnotes Demsetz' paper here.

${ }^{6}$ He proposed a statute that reads in part "(1) ... Municipal authorities would be permitted - and encouraged - to auction off franchises to the firm promising to provide cable service at the lowest rates to subscribers...

(2) States would be permitted, but not required, to regulate cable television companies as common carriers or public utilities. Realism would appear to dictate such a provision, whatever its wisdom, and any bad effects would be mitigated by provision (5) (a) below. ... (4) The FCC would be forbidden to regulate cable television, with three exceptions... (5) An Office of Cable Communications would be established in the federal government. It would have several functions (none regulatory): (a) To evaluate state and local regulation of cable television, to advise [on this] and to submit to Congress proposals for modifying state or local regulatory authority where such a course seemed indicated." (Posner, 1972: 126-7)

7 "To what degree should legislation and regulation replace the market in the utilities or in other industries and what forms should such legislation take? It is not the objective of this paper to provide answers to such questions." (Demsetz, 1968: 65).

8 "We are left, then, with a set of alternative approaches to the regulation of cable monopoly, no one of which is free from substantial difficulties. A period of experimentation would seem to be indicated." (Posner, 1972: 117)

${ }^{9}$ Stigler (1968: 19) noted that using the auction procedure "can thus economize on transaction costs". Posner made minimal but not insignificant comments on the transactions costs of the various options. Non-regulation: "A contractual solution to the problem of cable monopoly could turn out to be quite costly; whether it would 
Telser $(1969,1971)$ objected that franchise bidding gives no assurance that output will be priced efficiently in terms of marginal cost. Demsetz (1971) responded that marginal cost pricing was of secondary importance to his paper, and furthermore doubted whether regulation leads to more efficient pricing than an appropriately elaborated bidding scheme.

Peacock and Rowley (1972) questioned whether the production function was independent of the choice between competitive bidding and utility regulation. Regulation was likely to involve greater X-inefficiency, and less innovative competition. However, the bidding solution had problems associated with lack of parity at contract renewal and with ensuring that contractual commitments were in fact honoured. They noted that "in many decreasing cost situations the scale economies at issue are large but not momentous". They were led to propose a "competitive solution" because "Competition in production simultaneously widens the freedom of choice of individuals (workers who can shop around between independent suppliers) while substantially reducing discretionary power within the affected markets." They recognised that this solution might not be highly stable and was vulnerable to collusion, hence it would involve especially vigilant antitrust measures to enforce competition in the market place and to prevent concentration. Also, "market structure would be a matter for ongoing concern and perhaps for periodic regulatory adjustment".

Williamson (1976) and Goldberg (1976) expanded on the concerns about competitive bidding. They argued that such an approach would have other problems of its own, for example in terms of exposure to risk and the costs of contracting to deal with uncertainty and changing circumstances. Williamson illustrated this by the difficult experience of franchise bidding for CATV in Oakland, California. Goldberg argued that many of the problems associated with regulation lie in what is being regulated, not in the act of regulation itself. While not ruling out franchising with long-term or short-term contracts, Williamson and Goldberg suggested that rate of return regulation, despite its limitations, might on balance be the most efficient way to deal with the problems posed by long-term monopolistic utility investments in the face of uncertainty.

Subsequent empirical work (Zupan, 1989a,b) suggests that the Oakland experience was not typical of franchise bidding for cable TV. Zupan concluded that the approach has in fact worked quite well. ${ }^{10}$

or not is an unstudied empirical question' (p. 113). Franchise regulation [ie bidding]: “... the fixed concession method deprives the franchise system of one of its most attractive features, ease of administration, since when the franchise is awarded to the high bidder the process of choosing among applicants involves a minimum of administrative machinery and official discretion" (p. 114), although "when the cable company asks for a modification of the contract by virtue of an unforeseen change in circumstances, the public body may react ineffectually or perversely." (p. 116) Rate regulation: "The costs of regulation are commonly measured by the budgets of the regulatory agencies; but this procedure greatly understates the true costs. It ignores not only the legal and other expenses that are imposed on regulated firms ... but also the considerable indirect costs of regulation arising from ... the adaptive responses that firms will make ... and the perverse applications of regulation ..." (p. 117).

10 "Ex ante competition for franchise awards as well as the informal and formal rate control mechanisms possessed by most local franchisors appear to be quite successful at preventing monopoly pricing. In terms of fulfilling their contracts, furthermore, operators behave much better than is commonly believed. Reneging is infrequent and, when it occurs, it appears to reflect unforeseen changes in market information." (Zupan, 1989a: 439). 
However, the Williamson-Goldberg view seems to have prevailed, at least in the economics literature. Many distinguished writers on regulation simply do not discuss the concept of competition for the market or franchise bidding with respect to utility networks. ${ }^{11}$ Those who do discuss it seem broadly to accept the views of Williamson and Goldberg rather than those of Demsetz and Posner. ${ }^{12}$ Williamson's classification of bidding frameworks (once-for-all, incomplete long-term and recurrent short-term) seems to have been used in practice. ${ }^{13}$

\subsection{Competitive bidding and utility regulation in practice in the UK}

Over the last two decades, both types of policies - competitive bidding and utility regulation - have been adopted as part of the shift in emphasis from the public sector to the private sector, not least in the UK. In the 1980s there was considerable use of franchising and short-term contracting out for services such as refuse collection, catering and cleaning that had hitherto been provided by the local authorities, the National Health Service and the Ministry of Defence ${ }^{14}$. In the 1990s the Public Finance Initiative (PFI) and its successor the Public Private Partnerships (PPP) put out to competitive tender, typically on long-term (twenty to thirty year) contracts, the financing, building and operation of roads, bridges, schools, hospitals, prisons, government accommodation, computer systems, Ministry of Defence training simulators, and other activities. ${ }^{15}$ At the end of 2001 over 400 PFI projects were in force, committing Government departments to future expenditure in excess of $£ 100$ billion $^{16}$. Results to date seem to have been positive ${ }^{17}$.

Over the same period, privatisation of the British utility industries (telecommunications, airports, gas, electricity, water and rail) transferred the assets,

\footnotetext{
${ }^{11}$ E.g. Breyer (1982), Beesley (1992, 1997), Newbery (1999), Peltzman and Winston (2000), Joskow (2000).

12 "Franchise bidding is hardly a breakthrough in natural monopoly technology.... A number of experiments with franchise bidding have been conducted, and virtually no promising results have been obtained. Williamson's study of the failure of franchise bidding in cable television is particularly to the point here." Schmalensee (1979). "The Chadwick-Demsetz proposal is an ingenious scheme if the contract in question is simple (as with taxi licence plates). There are no doubt some economic activities where franchising would be an attractive scheme. But we are concerned with industries [ie natural monopolies] in which the difficulties of contract specification and administration would be immense." Vickers and Yarrow (1985: 30). "In practice, franchising has been successful in a number of fields.... However, there are many industries where franchising cannot work, at any rate in this simple form, and the industries described later in this book (energy, telecommunications, water, etc.) provide leading examples.” Vickers and Yarrow (1988: 111). “...if investment in specific assets is important, as in major parts of the utilities, there is a serious danger either of underinvestment or of ineffective competition for franchises. Competitive bidding is therefore unlikely to be very useful for capital-intensive elements of natural monopoly industries, and its potential lies in less capitalintensive areas." Armstrong, Cowan and Vickers (1994: 129). "As Armstrong, Cowan, and Vickers argue, franchising works best for straightforward products that involve low sunk costs, such as supplying licence plates for taxis, but in sectors such as the utilities, conditions are very different." Baldwin and Cave (1999: 268, in chapter 20 entitled Franchising and its Limitations). Foster (1992: 202) also emphasises the disadvantages noted by Williamson and Goldberg.

${ }^{13}$ For example, it is incorporated into a Best Practices Guide: Implementing Power Sector Reform, prepared for USAID by The Regulatory Assistance Project (Gardiner, Maine and Montpelier, Vermont) and implemented by The Energy Group, Institute of International Education, Washington DC, 2000.

${ }^{14}$ E.g. Hartley and Huby (1986).

${ }^{15}$ E.g. H M Treasury (1993), Brealey, Cooper and Habib (1997), Grout (1997), National Audit Office (1999, 2001), Pollitt (2000).

${ }^{16}$ National Audit Office (2001: 1).

${ }^{17}$ E.g. National Audit Office (1999), Pollitt (2000).
} 
management and operation of these sectors - some 15 per cent of Gross Domestic Capital Formation $^{18}$ - to the private sector. The utility companies were then subject to regulation of prices, investment and quality of service etc.

However, the comparison between the arrangements has not been precisely as envisaged in the earlier debate. The regulatory frameworks for the privatised UK utilities reflect a conscious attempt to avoid, or minimise as far as possible, the problems associated with traditional US utility regulation. This was done in two main ways. ${ }^{19}$ First, the socalled RPI-X type of inflation-related price cap was used for the monopoly networks. This was intended to provide better incentives to efficiency and innovation than US rate of return regulation, and to pass the resulting benefits to customers over time (Littlechild, 1983). Second, the monopoly networks were required to make access available to all interested users at regulated and non-discriminatory rates, and customers were allowed to choose their supplier. This made it possible to introduce competition to provide services across the networks, at both wholesale and retail levels.

Experience has varied between sectors and over time. However, competition is now flourishing in many activities, notably in telecommunications and in the production or generation and retail supply of gas and electricity. The gas and electricity regulator Ofgem (2002) has been able to announce the removal of all remaining price controls on retail supply, and the telecommunications regulator Oftel (2002) envisages this as possible before too long. These newly competitive activities account for a varying but substantial proportion of the costs of the utility industries. For example, generation and supply, both now competitive, account for over two thirds of the price of electricity.

For the most part the combination of competition across the networks and incentive regulation of the networks themselves, coupled with the shift to private ownership, has been remarkably successful in terms of improved efficiency, lower prices, better quality of service and innovation in products and production ${ }^{20}$. Increasingly, other countries have adopted similar policies, including many states in the US.

\subsection{Further examination of experience with competitive bidding}

In the light of this experience, some might argue that it is now of less interest and importance to examine competitive bidding alternatives to regulation of the remaining network monopolies. However, those remaining monopoly activities are so substantial that further improvements are still worthwhile. Whether regulation is the best means of achieving this, and what kinds of regulation, are still the subject of active debate ${ }^{21}$. In addition, conventional privatisation and regulation may not be politically acceptable in certain contexts, so that the feasibility and desirability of competitive bidding is of even more direct interest. Another possibility is a modification of the regulatory framework to

\footnotetext{
${ }^{18}$ Pollitt (2000: 1).

${ }^{19}$ For discussion, see (e.g.) Beesley (1992, 1997), Armstrong, Cowan and Vickers (1994), Newbery (1999).

20 "It is difficult to argue against the proposition that the privatisation of utilities has resulted in very considerable benefits for customers, shareholders, the government and in many cases workers." (Pollitt, 2000:30).

${ }^{21}$ E.g.Better Regulation Task Force (2001)
} 
increase efficiency. ${ }^{22}$ This could include enabling or encouraging the utility companies themselves to do more contracting out ${ }^{23}$.

Following Goldberg's suggestion ${ }^{24}$, a useful first step is to examine cases where this has actually been done. A recent long-term PFI contract that provides for the operation, maintenance repair and renewal of the whole of a substantial electricity network is therefore of particular relevance. This is the thirty-year contract between Seeboard Powerlink (SPL) and London Underground Limited (LUL), which began to take effect in August 1998. It followed a competitive process whereby the contract was awarded to the qualified bidder offering to provide the specified service at the lowest price.

By studying this and other relevant contracts it is possible to understand how the parties perceived and dealt with the risks and other problems of franchise bidding and longterm contracts ${ }^{25}$. One can also begin to assess how far the problems generally identified with a franchise bidding or contractual approach to a network monopoly are applicable in this particular case. This seems a useful basis for a subsequent exploration of what might be involved in competitive bidding for long-term or short-term contracts as an alternative or supplement to the present form of utility regulation, in the UK or elsewhere.

Section 2 of this paper briefly describes the size and nature of the contract between Seeboard Powerlink and London Underground (henceforth the SPL/LUL contract). It explains why London Underground decided to contract out its electricity network on a long-term contract. An Appendix to the paper examines in more detail how the SPL/LUL contract allocates risk between the parties. It explains how each party, particularly London Underground as the party responsible for proposing and letting the contract, has sought to protect itself against risks associated with performance and price.

Section 3 examines the contract, and subsequent experience under it, against the potential problems with long-term contracts identified by Williamson. This includes comparison with the particular problems experienced in the Oakland CATV franchising process. Section 4 compares this form of contract against alternatives such as continued public ownership, a series of shorter-term contracts, a regulatory-type arrangement involving cost-plus rate of return or an RPI-X constraint, and privatisation plus utility regulation. Section 5 concludes.

\footnotetext{
22 "Where should price regulation go from here? Although the previous method has had its successes, it is now time to move on. The starting point must be the establishment of agreed objectives, supporting principles and explicit procedures for regulating the UK's infrastructure network assets. Such objectives and procedures should be long-lasting - to minimise regulatory uncertainty - and must give balanced incentives to achieve economic efficiency and satisfy customers' interests. They should be subject to change only in extreme circumstances via an agreed process." Jackson (1999: 31).

${ }^{23}$ The utilities increasingly use competitive outsourcing for various input requirements such as transport, IT systems, metering, tree felling, trenching, construction, etc. See also Littlechild (2001).

24 ، ... the administered contracts framework opens up new areas of search for innovations in regulatory institutions.... A second source of innovation is observation of the behavior of privately contracting parties. How do businessmen design, police, and adjust their long-term relationships? Can any of the techniques that have evolved in the private sector be fruitfully transferred to the public sector?" Goldberg (1976: 445).

${ }^{25}$ The present paper differs from many other studies of long-term contracts - such as Joskow $(1985,1987)$, Goldberg and Erickson (1987) and others in Williamson and Masten (2000) - in that the understanding is based not only on the written content of the contract itself, but also on discussions with representatives of the parties involved.
} 


\section{The SPL/LUL Contract}

\subsection{The size and nature of the contract}

London Underground Ltd (LUL) has over 270 stations and over $400 \mathrm{~km}$ of track. It has traditionally supplied most of its own electric power. To that end it has two generating stations (Lots Road and Greenwich) with total capacity of nearly $300 \mathrm{MW}$, and a substantial electrical network with nearly $1500 \mathrm{~km}$ of cabling that distributed 900 million $\mathrm{kWh}$ of power in 1997/98. It is about 5 per cent of the size of the regional utility London Electricity in terms of cable length and total distributed power load. However, LUL's remote control system is more sophisticated than that of any regional electricity company because of the need to serve and protect some three million customers underground. It is the largest non-utility electricity network in the UK, exceeding those of the various ports, airports and industrial estates.

In 1995 LUL began to consider awarding a long-term contract to operate, maintain, finance and renew its high-voltage power distribution network ${ }^{26}$. This would also include, on an interim basis, fuel processing through LUL's own generation plant, but not the purchase of electricity through the National Grid supply points. Payment to the contractor would derive mainly from an availability charge for providing the electricity distribution network services. Subject to satisfactory qualifications, the contract would go to the party bidding the lowest availability charge over the term of the contract, which was specified as thirty years.

A Performance Specification was based on LUL's existing standards, augmented to cover the new situation, and backed up by a comprehensive survey of existing assets. The assets would be leased to the Contractor and would have to be handed back in a specified (and improved) condition at the end of the contract. Regimes were defined for operation and maintenance, and for renewal and upgrades. Subject to these constraints, management of the network would be a matter for the Contractor. That would include the nature and extent of initial investment to cope with the decommissioning of LUL's main power station at Lots Road and the replacement of assets to meet increasing demand ${ }^{27}$.

Financial penalties, or more precisely liquidated damages ${ }^{28}$, would be applied if trains were delayed or stations closed as a result of failure to provide electricity. There was also a deficiency points regime that could ultimately lead to termination of the contract in the event of failure to meet the specified standards. Most of the LUL Power System employees (over 300) were to transfer to the winning contractor, and their interests had to be protected.

\footnotetext{
${ }^{26}$ Buchanan and Hardy (1999) provide useful technical background.

${ }^{27}$ The investment programme would be in two parts. The first part, to be completed in the first five years, would be a programme of Initial Works called for by LUL. This comprised (in order of magnitude) completion of the upgrading of the Northern Line power system that had been started by LUL, the Emergency Supply Plan to install backup batteries and overhaul the standby equipment, renewal of the SCADA (Supervisory Control And Data Acquisition) system for the power system control equipment, and certain smaller works. The second part, spread over the contract life, would be a package of works determined by the Contractor as necessary to ensure compliance with the performance specification. SPL's package comprised mainly rectifiers, switchgear and cables plus renewal of a major switchboard.

${ }^{28}$ Liquidated damages are required to be a genuine pre-estimate of a party's loss as a result of failure to meet the contract. They stand in contrast to an ex-post calculation of actual damages.
} 
The contract was designed and let under the terms of the Government's Private Finance Initiative (PFI). From start to finish - from the decision to go for a PFI contract to signing it - the process of preparation, pre-qualification, bidding and due diligence lasted about three years.

On 13 August 1998 LUL awarded the contract to Seeboard Powerlink (SPL). This was a consortium put together by the regional electricity company Seeboard, and including the engineering contractor BICC (now Balfour Beatty) and the power equipment manufacturer Asea Brown Boveri (ABB). The press release noted that the contract was worth over $£ 1$ billion, and would involve over $£ 100$ million capital investment during the first five years ${ }^{29}$.

\subsection{Why did LUL decide to contract out its electricity network?}

The London Underground system has provided the bulk of its own power since about 1900, when the original underground companies could not obtain adequate supplies outside. In recent years it had a Power System Engineering Department with well over 300 staff. Arrangements for operation and maintenance were broadly satisfactory, but this was not the case with respect to capital investment. As a public sector organisation LUL depended on the Government for funding, on an annual basis. It could not borrow without impacting on the Public Sector Borrowing Requirement (PSBR). In addition to the macroeconomic and political determinants of the level of the PSBR, there were many other claimants for Government funding, and investment in LUL was not generally regarded as the most efficient use of funds. Moreover, within LUL, investment in the power system had to compete with other projects, and in recent years the new Jubilee line had taken the bulk of the organisation's resources. Since the power system assets generally had long lives, the case for new investment was not perceived as compelling and there was a lack of new investment $^{30}$. At the time of announcing the contract, LUL estimated that it had a $£ 1.2$ billion investment backlog in the Underground as a whole. ${ }^{31}$

During the 1980s, LUL proposed to close Lots Road power station and replace it with a backup system using batteries, to avoid undue reliance on the National Grid supply. LUL applied to the Government for funding. The Government suggested that LUL should

\footnotetext{
${ }^{29}$ The undiscounted contract revenues were nearer $£ 1.5$ billion and the discounted value nearly $£ 0.5$ billion. The undiscounted capital expenditure was over $£ 250$ million over the contract life.

${ }^{30}$ For example, Lots Road power station was first commissioned in 1905, and was then the largest power station in Britain. It was last modernised in the 1960s, and is the oldest working power station in Europe. It was scheduled to close in 1990 but is still open over a decade later.

${ }^{31}$ This presumably included the investment covered by the SPL/LUL scheme. Much higher figures have subsequently been used in the context of proposals to introduce PPP schemes to improve and maintain other LUL services. "As I explained to the House last year, we inherited an investment backlog of £1.2bn. We intend to modernise the Underground through a $£ 7$ bn public/private partnership which will bring long-term stability to the investment programme. ... This means that for the first time in living memory London Transport will know what it can spend on investment for years to come. Until now, London Transport investment plans have been approved in theory for a three year period; in practice, they were chopped and changed every year. I cannot over-estimate to the House the value of being able to plan ahead in this way and to secure greater productivity in the use of capital." London Underground Statement by The Rt Hon John Prescott, MP, Deputy Prime Minister Published 16 June 1999. "[The PPP proposals] will drive investment of $£ 13$ billion over 15 years, with $£ 8.7$ billion spent on enhancements, and $£ 4.3$ billion on maintenance" London Underground Public Private Partnership: The Offer to Londoners, Government/CBI presentation 10 April 2001.
} 
instead use the Private Finance Initiative to fund the new batteries ${ }^{32}$. LUL took the view that installing the batteries alone would not be a sufficiently attractive project for the private sector. In 1995 it decided instead to explore the possibility of contracting out the whole of its electric power system and associated investment.

A secondary benefit of contracting out, although not the prime trigger, was the prospect of innovation. There was no lack of intellect at LUL, but by virtue of its unique position it was relatively insular. It saw advantage in exploring new ideas, in testing its own thinking about the best way to re-power the system against thinking by others. The desire for innovation had an impact on contract design. ${ }^{33}$ Also, becoming part of an engineering company active in the commercial market was a potential advantage, to management and staff, in terms of incentives and opportunities.

\subsection{Why did LUL choose a long-term contract?}

The PFI process itself did not require a long-term contract. LUL wanted the contract to be of sufficient duration to encourage the benefits of a comprehensive investment programme to move away from the annual nature of the previous arrangements. It wanted to encourage the Contractor to make proper long-term provision, and not to do the least necessary to scrape through. It also wanted to avoid giving the Contractor an incentive to do all the investment early then run down the system.

After its internal consideration of the issues, LUL went out to industry consultation with its proposed scope and contract form, including a suggested duration from 20 to 40 years. It got 73 responses and talked to 20 of the respondents. There was a good mix of potential players (electricity industry participants, manufacturers and merchant banks). The responses gave confidence that the proposed package and duration were on the right lines. Potential contractors put forward no alternative proposals. Financial advice to LUL was that an even longer-term contract, up to 50 years, might have produced a lower price over time, but LUL was apprehensive about the risks involved in such a long duration. It finally settled on 30 years. This was about half the typical life of most of the assets ${ }^{34}$. The contract provided that the new assets would revert to LUL with a similar average age profile as the existing assets at the beginning of the contract ${ }^{35}$.

\section{The problems identified by Williamson}

Williamson (1976) identified three main potential problems about long-term contracts for franchising out natural monopolies:

\footnotetext{
${ }^{32}$ Both the previous Conservative Government and the incoming Labour Government had ruled out privatisation of LUL. They had respectively proposed Private Finance Initiatives and Private Public Partnerships for various other projects.

33 "To give the Contractor maximum scope for innovation, the contract was to be performance based. The Contractor would have considerable freedom of action within substations, where only LUL standards such as the fire performance of materials would apply, but would be required to work fully to LUL standards in customer areas such as stations." Buchanan and Hardy (1999: 3).

${ }^{34}$ The switchgear, rectifiers and transformers, that constituted the bulk of the required investment, had an assumed life expectancy of 50 to 55 years; for the cable it was 65 years.

${ }^{35}$ The aim was not a lower average age profile. Rather, it was hoped that at reversion the assets would have a better spread of age, with a flatter reinvestment profile than at the beginning.
} 
(1) The initial award criterion is apt to be artificial or obscure;

(2) Execution problems are apt to develop in the price-cost relationship, in other performance aspects, and in political respects;

(3) Bidding parity between the incumbent and prospective rivals at the contract renewal interval is unlikely to be realised.

He illustrated these by the experience of granting community antenna television (CATV) franchises in Oakland, California.

This section compares the SPL/LUL contract and experience against the Oakland CATV experience, with respect to each of these potential problems. How did SPL and LUL try to deal with the potential problems and with what success so far?

\subsection{Artificial or obscure initial award criterion}

Williamson points out that there are difficulties if the criteria for the initial award include not only price but also a set of different quality dimensions. Similarly, there are difficulties if price itself is not a single parameter but a vector, e.g. a complex pricing schedule for variable load, varying by time or according to particular future circumstances. "The upshot is that, although franchise awards can be reduced to a lowest bid price criterion, this is apt to be artificial if the future is uncertain and the service in question is at all complex." $(\mathrm{p} .81)^{36}$

In the Oakland CATV example, bidders were to provide a basic System A and also an optional System B which would offer special programming and other services. However, the mix of programming and other services in System B was left unspecified and the charges for System B were to be determined later by the franchisee with the approval of the City Council. The franchise was awarded on the basis of the lowest bid price $\mathrm{X}$ to provide System A. Williamson comments that this simplified the award criterion, but the promise to supply that system cheaply proved to be specious because in the event most subscribers took both systems. ${ }^{37}$

LUL was faced with less uncertainty about demand and technology than was Oakland, given that CATV was new whereas the underground railway was a long-existing service. LUL was advised that no new technology was imminent. However, there was still some uncertainty about the future demand for underground travel, not least about government policy thereto. There were also differences of view about the best technical solution to adopt to replace the existing generating station and to meet the projected demand growth. Different solutions would have different implications for the costs and risks of meeting the quality specifications. The electricity network represents a complex

\footnotetext{
${ }^{36}$ Unless otherwise attributed, quotations in this section are from Williamson (1976).

37 "The lack of attention to System B ... may well have contributed to "adventurous" bidding on the part of Focus [the lowest bidder by a factor of two].... To have regarded System A ... as the "basic system" was misguided. Over 90 percent of the subscribers took the combined A/B service, although the additional service thereby obtained was relatively mundane... The rate on the combined service, however, was threeand-a-half times as great as [on] the basic System A service.... The possibility that the Staff [of the Office of General Services, City of Oakland] was gullible and deliberately misled during the[se] precontract discussions cannot be dismissed.... Whatever the case - given the demand and technological uncertainties associated with CATV and the complexity of the service, in quality and product mix respects - reducing the award criterion to the lowest bid price for System A resulted in a strained and perhaps bogus competition." (p.99)
} 
service in respect of quality, and there was extensive potential scope for varying the price, risk and quality paths over a thirty-year horizon, with possible implications for other aspects such as flexibility, innovation etc. An additional complexity was the important safety aspect, and the greater financial and political impact of the LUL contract compared to the CATV franchise.

LUL resolved these issues as follows. It established four criteria for prequalification: engineering, safety, human resources, and commercial. The engineering criterion included the knowledge, experience and reputation necessary to do the work and the acceptability of the proposed technical solution for the Initial Works. The safety criterion included previous experience working on railways and the ability to take forward a dynamic safety case for the underground. ${ }^{38}$ The human resources criterion included the ability satisfactorily to take on the bulk of the existing LUL Power System staff including their pension arrangements. The commercial criterion included cost and risk sharing. Essentially, the first three criteria had to be met; subject to this, commercial issues would be the determining factor.

Since no one organisation could expect to have all the necessary expertise and resources, consortia of electricity companies, manufacturers and banks formed naturally. Four consortia pre-qualified. They were reduced to two at the formal tender stage. These two fully met the first three criteria39.

The quality issue was determined by specifying the required performance. It was to be expected that bidders would differ with respect to the technical solutions proposed, which as noted could have implications for performance, but the liquidated damages would make LUL good against any differences here. These liquidated damages and the deficiency points process, and the other provisions of the contract discussed in the Appendix, were intended to keep the Contractor within acceptable limits.

The allocation of risk as between LUL and the Contractor would have significant implications for both parties, and could not be ignored in assessing the bid price. Consequently discussions proceeded with both main bidders to secure a mutually acceptable allocation and capping of risks, so that the bids could be evaluated on a common basis with respect to price40. In particular, the risks associated with demand growth were assumed by LUL.

It was necessary to reduce the potential multi-dimensionality of price to a single parameter. The bids were therefore required to be formulated in terms of a constant revenue stream in real terms (i.e. adjusted for RPI) over the thirty years. ${ }^{41}$

\footnotetext{
38 "Maintaining a dynamic safety case" is a Rail Inspectorate requirement. It means identifying risks and saying how they are to be addressed, and keeping up to date with changes in the system. The Contractor is obliged to support LUL in securing this aim, and to get accreditation itself. In future SPL may have its own proportion of the safety case.

${ }^{39}$ The bidders were surprised at how extensively LUL vetted them. It was important to LUL to protect against any subsequent incompetence and to ensure credibility with Government and staff. Most of the latter would be transferring to the Contractor.

${ }^{40}$ There were differences in approach between the two main bidders. One addressed the risk issue early, saw it as a "show-stopper" initially, then translated the risk into a large premium in the bid price. The other bidder did not initially consider the level of risk as unacceptable, given its previous experience in operating electricity distribution networks, but later came to see the significance of it.

${ }^{41}$ RPI is the Retail Price Index, the standard measure of inflation. There is some adjustment in the contract revenue stream to reflect the incidence of investment (e.g. between years 7 and 15 there is a big investment in
} 
With the LUL contract there was no concept of bidding to provide an additional and ill-specified System B at charges to be determined later ${ }^{42}$. The bid was solely to provide the well-specified basic service (System A) that LUL wished to purchase, and award of the contract was based on that bid ${ }^{43}$.

\subsection{Execution problems}

\section{(i) price-cost relations}

Williamson writes

"In circumstances in which long-term contracts are executed under conditions of uncertainty, fixed price bids are apt to be rather unsatisfactory. If the environment is characterised by uncertainty with respect to technology, demand, local factor supply conditions, inflation, and the like, price-cost divergences and/or indeterminacies will develop." (p. 82)

He notes that some of these divergences can be reduced by indexation of prices, but

"This, however, is a relatively crude correction and unlikely to be satisfactory where there is rapid technological change or where local conditions deviate significantly from the index population." (p.82)

In his discussion of the Oakland CATV experience, Williamson questions whether the lowest and hence winning bid was close to per unit production cost. This is because of doubt whether the bidding process was competitive, because the more relevant System B prices were negotiated subsequent to the bidding competition, and because true cost levels are difficult to ascertain (the latter because of vertical integration, high inflation and lack of auditing capability). He does not discuss problems of divergence between price and costs over time, other than to note that the contractor and the staff are "involved in a long-term bargaining relationship over prices and costs in which political interests, bureaucratic interests, and franchise viability all play a role." (p. 99)

As regards the applicability to the LUL contract of the general factors mentioned by Williamson, relevant technology was not expected to change significantly. Uncertainty about demand was a risk assumed by LUL, and any divergences from its projections are costed and remunerated according to principles laid down in the contract. London prices of labour, office space and some other inputs might be higher than in the UK generally, but there was no strong reason to expect that the divergence would vary significantly over the next thirty years. The contract reflects inflation by means of the standard Retail Price Index (RPI).

The main possible divergence between price and cost derives from the fact that the subcontracts to the contract are all price-related to the BEAMA index of electricity

asset replacement), and known changes in circumstances (e.g. the closure of Lots Road). There is also some smoothing of revenue where that would be beneficial to both parties.

42 There was the prospect of further work to implement Variations but, unlike the situation with the Oakland CATV systems, the bidder was not expected to propose the content of such work, and the basis for pricing any such work was made clear in the contract.

${ }^{43}$ There was scope for a bidder to offer an additional bid for an innovative solution to the provision of the basic service, if it thought that this would be of advantage to LUL. Only one bidder availed itself of this opportunity, and proposed that the bidder retain the Lots Road site after decommissioning the generation station there. LUL had previously evaluated this option and considered it less valuable than retaining the site itself. The final choice was therefore on the basis of uniform assumptions about site ownership. 
contracting costs for heavy engineering work, rather than to RPI, because the subcontractors would not accept them otherwise. The possibility of a discrepancy between RPI and the BEAMA index was acknowledged and priced into that element of the SPL bid.

Electricity supply itself was not included in the contract (as distinct from the costs of processing fuel purchased by LUL). Hence, the possible problems of indexing the costs of electricity supply did not arise ${ }^{44}$.

None of the factors that caused Williamson to doubt whether the winning bid in Oakland was close to per unit production cost apply in the case of LUL and SPL. There was effective competition, there was no System B, and costs were well understood by all parties. The winning bidder and LUL are indeed involved in a long-term relationship, but it is a contractual rather than bargaining relationship. Political interests, bureaucratic interests, and franchise viability have not hitherto played a significant role ${ }^{45}$.

\section{(ii) other performance attributes}

Williamson argues (pp. 82-3) that, if the contract is insufficiently specific about quality of service and fails to stipulate monitoring and accounting procedures, this gives latitude to the franchisee. Enforcement of technical standards requires a policing apparatus, which in turn is likely to require a specialised agency since consumers are unlikely to have the necessary expertise. A common quality standard for all bidders may not suffice to ensure that the chosen technical solution meets the standard. Penalty clauses can help forestall the failure to meet the standards, but successful bidders can often have terms renegotiated to their advantage. Accounting ambiguities and a disinclination to allow winning bidders to fail permits franchisees to use the threat of bankruptcy during renegotiations. Monitoring and accounting control techniques can prevent such outcomes, but this amounts to a quasiregulatory relationship.

The Oakland experience was that "the stipulation that the CATV system be installed and maintained in accordance with the 'highest and best accepted standards' of the industry coupled with technical specifications did not yield a well-defined quality outcome." There were sufficient customer complaints about quality of service "that the Staff, unable itself to assess the quality of service, has arranged for a consultant to test the degree of compliance with technical requirements." (p. 99)

In contrast, the SPL/LUL contract is very precise about quality standards and monitoring procedures. There is a specialised monitoring agency in the form of the 30 staff retained at LUL for this purpose. To supplement the prescribed quality standards there are operating Regimes familiar to both the monitoring and the transferring staff. The provision for liquidated damages serves a similar purpose to penalty clauses, but more effectively. ${ }^{46}$

\footnotetext{
${ }^{44}$ In commenting on possible flexible pricing techniques to deal with changing costs, Goldberg (1976: 438) says "Prices might be tied to spot market prices, but spot markets for most regulated industries seldom exist (nor would the likelihood of their existence be much enhanced under alternative nonregulatory regimes)." In fact spot markets do now exist for electricity and gas, and their existence in the UK and no doubt elsewhere was indeed greatly enhanced by deregulation (including privatisation, liberalisation and restructuring).

${ }^{45}$ Subsequent PPP contracts for other London Underground services have become a political issue, however, as explained below.

${ }^{46}$ In the event of a dispute, penalties are difficult to enforce unless related to costs, whereas genuine and agreed pre-estimates of loss are difficult to challenge. The contract provides that "All sums payable by the Contractor to LUL pursuant to Clause [ ] shall be paid as liquidated damages and not as a penalty and the Parties acknowledge that such sums are a genuine attempt to pre-estimate the loss which will be suffered by LUL in the event of any such failures in performance or breach of this Contract."
} 
The liquidated damages are supplemented by the deficiency points regime with its process of warnings. There has been no renegotiation of terms.

Nor are there accounting ambiguities: the Contractor needs to secure audited accounts commensurate with standard accounting practice, and the financial agreements with the lending banks require profits to be stated in accordance with Standard Accounting Practice (SAP 9). The contract makes further specifications (e.g. that expenditure is to be expensed not capitalised). LUL has the right to audit and take copies of all records, including the asset and contracts register. The parties operate an "open book" policy. The threat of bankruptcy is not available to the Contractor because LUL (and the Government) required parent company guarantees, and the lenders insisted on reserves being built up.

\section{(iii) politics}

Williamson argues that:

"in circumstances in which renegotiation is common and perhaps vital to the profitable operation of a franchise, political skills assume special importance. Prospective suppliers who possess superior skills in least cost supply respects but who are relatively inept in dealing with the franchising bureaucracy and in influencing the political process are unlikely to submit winning bids... Indeed, if franchisees are subject to less stringent profit controls than regulated firms (where the latter are subject to rate of return control) it may well be that franchising encourages greater political participation." (p. 83)

In the Oakland CATV example Williamson argues that, for several reasons, the lowest bidder is likely to have engaged in "buying in":

(1) Its bid was half the second highest and one-third the third highest;

(2) The timing and nature of its reorganisation suggested a "foot in the door" strategy;

(3) The franchising authority affirmatively regarded its local bidding status;

(4) It engaged in extensive renegotiations with evident success in terms of deferred outputs, increased fee, reduced damages, extended deadlines and increased rates. increased rates.

In the LUL case, there was not expected to be any renegotiation, and political skills did not assume any special importance. Since the bidders were large and experienced companies combined in consortia, any individual company's "ineptness" in dealing with LUL was unlikely to be significant. ${ }^{47}$ Once the decision to adopt the PFI process had been taken, the bidding and award process seems to have been essentially independent of the political process.

As regards Williamson's four points about political aspects of the CATV process, none seems to have applied in the LUL case:

\footnotetext{
${ }^{47}$ Presumably Williamson's reference to "political skills" is not intended to underrate the ability to negotiate and then liase effectively with potential clients, which seems a relevant and positive attribute. As a matter of interest, LUL noted that one bidder was more aggressive than the others in suggesting it could run the network better than LUL, and LUL felt that two of the bidders were less strong than the other two in that they did not use their full potential. However, the decision as between the two main bidders was on the commercial criterion, essentially a matter of price.
} 
(1) The bids, although not made public, were of a similar magnitude (within a few percent) rather than differing by factors of two or three;

(2) There was no reorganisation of the winning consortium during the bidding process $^{48 ;}$

(3) The "local bidder" London Electricity competed but was not part of the winning consortium;

(4) There was no renegotiation after the award of the contract.

\subsection{Lack of bidding parity during contract renewal}

Williamson notes that if there is to be meaningful competition at the contract renewal stage, winners of the original competition should not be placed at a substantial advantage over non-winners. He argues that there is reason to believe that bidding parity will not obtain. One of these reasons is said to be expressly developed in the context of CATV. However, such an argument is difficult to find in the later discussion. The sub-section itself is re-titled "frictionless takeover or transfer" rather than "lack of bidding parity at renewal", and there is no explicit discussion of the latter topic. Nor was there any experience of renewal in Oakland at that time. Williamson's discussion focuses mainly on the City of Oakland's unwillingness to buy up the assets and terminate the contract prematurely. He attributes this partly to the human asset problems associated with specialised and experienced staff, and partly to the absence of unambiguous rules for valuing the CATV plant. Any attempt to take over the plant would have led to litigation expenses and delays.

LUL was conscious of the potential problem of lack of bidding parity at renewal. It recognised that complete parity would not be attainable. It also recognised that it was difficult to assess what factors would be relevant, and what circumstances would obtain, in thirty years' time. Since it was not clear what provisions would then be most appropriate, LUL considered it best not to write too much into the contract, nor to devote too much time and resources to this issue.

LUL nonetheless took several steps to make it as feasible as possible for another company to take over and run the electric power system at the end of the $\operatorname{contract}^{49}$ :

(1) The contract envisages that there will be a new tender after thirty years, and requires the Contractor "to take all reasonable steps required by LUL to facilitate the engagement of a successor contractor and/or the resumption by LUL of the provision of the services";

(2) The pre-existing assets, including the continuing investment necessary to renew and upgrade them to meet the Ultimate Reversionary Requirements (see Appendix), are made available to the Contractor but revert to LUL ownership. There is provision

\footnotetext{
${ }^{48}$ When SPL was declared the preferred bidder it organised a transition team separate from its bid team, to plan ahead, as did LUL, but the consortium members remained the same.

${ }^{49}$ LUL also structured the contract to give the bidder the tax benefits of its capital investment. This was reflected in the bid price and said to be a factor in the comparison with the Public Sector Comparator.
} 
for an asset audit by LUL at the end of the contract that can be challenged or corrected by the Contractor;

(3) The new assets required for the Initial Works are held in the Contractor's ownership in order to finance the up-front spend over the period of the contract and for tax reasons. LUL has the right either a) to purchase these new assets from the Contractor's capital-owning subsidiary at fair market value or to lease them at the greater of

a. agreed market rent or

b. the cost of maintaining the subsidiary plus a specified annual fee $\mathrm{e}^{50}$;

(4) There is an obligation on the Contractor to provide the IT systems and instruction manuals and intellectual property rights;

(5) LUL will obtain rights to the cable wayleaves at the end of the contract, and will own any land used to build substations;

(6) It is expected that staff would go to the new contractor at the end of the contract. The contract is acknowledged to be governed by Transfer Regulations that require that staff should transfer on the same terms of employment ${ }^{51}$. The contract precludes the Contractor from substantially altering the numbers or organisation of the employees providing the service, or making any significant change to the terms of their employment, during the 10 months prior to the expiry of the contract.

It is obviously hoped to avoid premature termination of the contract. Nevertheless, many pages of the contract are devoted to specifying the grounds for doing this, the steps to be taken, and the precise basis of termination payments to be made. So if premature termination were indicated, this should not be precluded by deficiencies in the contract.

\subsection{Summary and actual experience}

In sum, the nature and experience of the SPL/LUL bidding process and contract for the London underground has in many respects been the opposite of the corresponding process for Oakland CATV. The initial LUL award criterion was not artificial or obscure, and the resulting competition was effective rather than strained or bogus. Concerns about divergences between price and cost do not seem to loom large in the case of the SPL/LUL

\footnotetext{
${ }^{50}$ Since they have no market value outside of the LUL context they might be expected to transfer for a nominal price. Nearly all the capital expenditure is expensed rather than capitalised and depreciated, so there will not be much undepreciated capital expenditure at the end of the contract.

${ }^{51}$ The Transfer of Undertakings (Protection of Employment) Regulations 1981 (known as TUPE) provide that "employees employed by the previous employer when the undertaking changes hands automatically become employees of the new employer on the same terms and conditions. ... Thus employees' continuity of employment is preserved, as are their terms and conditions of employment under their contracts of employment (except for occupational pension rights)." (Employment Rights on the Transfer of an Undertaking, PL 699 (REV 1), Employment Department, no date, emphasis in original) Following negotiations with the trades unions, staff that transferred from London Underground were allowed to stay in the LUL pension scheme and continue to receive travel benefits.
} 
contract, either initially or prospectively. The quality standards were well defined and LUL's staff well able to monitor them. There is no evidence of political issues dominating the process, or of "buying in" by the winning bidder. Furthermore, LUL built into the contract a significant set of obligations to ensure, as far as reasonably possible, that another company could take over the assets and operate them at the termination of the contract period.

It is too soon to come to a final judgement on the SPL/LUL contract, since as yet it has only been operational for some three and a half years, and much of the contract has yet to be tested. But so far, the contract is working well. More attention is being given to property maintenance than under LUL operation, including the starting of a buildings data library. Significant improvements in maintenance cycles have been achieved. As of March 2002 the projected $£ 100$ million initial investment program is 90 per cent complete (plus an additional $£ 98$ million value of work done). Much of the initial investment has been in new batteries and station emergency power facilities, so the effects would not be expected to show up in normal running. Nonetheless, the network is now managed differently, and incentives are stronger. ${ }^{52}$ Performance of the power system is more satisfactory than it was under LUL's own management. Specifically, payment of liquidated damages for network failures has been significantly less in the first three years of the contract than it would have been if performance had matched the levels of the previous four years. There have been debates about monitoring, but generally this too is going well. ${ }^{53}$

Experience has suggested to the parties some aspects that, in retrospect, might have been done differently and also some scope for adjustment in future. For example, the deficiency points scheme could usefully have positive points for good performance to offset the negative points for poor performance, i.e. carrots as well as sticks. There might have been some provision for contract review every seven years or so, as provided for in more recent proposed PPP contracts. The provisions for LUL's detailed involvement in monitoring and design might have been relaxed. (To some extent they reflected LUL's previous responsibility for designing and operating the system, rather than the need for such involvement in future.) But for the most part these possible modifications to the contract are relatively minor. ${ }^{54}$ Where they are important they can be achieved over time as

\footnotetext{
${ }^{52}$ For example, whereas formerly it was simply an internal LUL management target to recover control within one hour of a remote control failure, now SPL receives a penalty under the Deficiency Points regime if control is not re-established within one hour. SPL has instituted a bonus scheme for its staff related to performance in relation to liquidated damages and deficiency points incurred (including with reference to the restoration of control within the hour).

${ }^{53}$ The contrast with work not covered by PFI/PPP contracts is also worth noting. “... under existing systems London underground projects are often late and suffer large cost overruns. The Jubilee Line Extension was 2 years late, and is still not running at full capacity despite a cost overrun of $£ 1400$ million. The Central Line resignalling work is 6 years late. London Underground enhancement works currently overrun by an average of 20\% more than budget." London Underground Public Private Partnership: The Offer to Londoners, Government/CBI presentation 10 April 2001.

${ }^{54} \mathrm{~A}$ few more examples: There would be advantage is co-locating the LUL interface staff with the Contractor's staff, perhaps on adjacent floors, to encourage teamwork without compromising the separate roles. The Contractor might have taken on lead responsibility for maintaining the safety case. SPL might have suggested a standard of getting to 85 per cent of locations within one hour rather than 100 per cent. As to the contracting process, both parties sought to ensure that those staff who would later be implementing the contract were involved at the negotiating stage, but afterwards there were occasional examples where operating staff were initially unclear where particular risks were allocated and why.
} 
experience and confidence grow, as indeed is now happening with the monitoring procedures.

\section{$4 \quad$ Alternative arrangements}

What does the SPL/LUL contract tell us about alternative ways to provide and operate LUL's electricity network? This section discusses the main alternative options: internal provision (in public ownership), a long-term contract, short-term contracts, and contracting out and/or private ownership subject to utility-type regulation. It then briefly extends the discussion to LUL's main business of underground railways.

\subsection{Internal provision versus bidding for a long-term contract}

Demsetz argued that it was feasible to put out to competitive tender a natural monopoly service, and that this would have certain advantages. Electricity distribution for London Underground has indeed been put out to competitive tender. It appears to be a service where competitive bidding for a long-term contract has, to date, demonstrated benefits compared to public ownership and operation.

Williamson, while sceptical about the benefits of franchise bidding in general, acknowledged that there were probably circumstances, such as local service airlines and possibly postal delivery, where regulation or public ownership could advantageously be supplanted by franchise bidding:

"The technology for both is well developed, demand is likewise well defined, and idiosyncratic skills appear to be negligible. Furthermore, displacement can be made without serious asset problems - since the base plant ... can be owned by government and other assets ... will have an active second-hand market." (p. 101)

Williamson did not include the network utilities in his list, and subsequent writers (as cited earlier) have also tended to exclude them. An exception is Domberger, who explicitly includes electricity distribution in his list of suitable candidates for franchising, for similar reasons as given by Williamson. ${ }^{55}$

Electricity distribution for London Underground in fact has the features mentioned by Williamson and Domberger. The technology is well developed and relatively static. The service can be defined with precision. The demand is well defined and without significant fluctuations. To the extent that there is a risk of uncertain demand over time, the contract leaves this with London Underground. The necessary operational skills are largely replicated in the electricity and contracting industries generally. Retaining "base plant" in London Underground's ownership, and transferring the specialised staff with the contract, together address the "displacement of assets" problem.

The SPL/LUL contract illustrates the time, cost and commitment required to formulate, tender and award the contract for an electricity network. This is no doubt to be

\footnotetext{
55 "It is clear from our examination of franchising, however, that its greatest scope lies in areas where technology of production is relatively simple and static, where the product or service can be specified with precision, and where significant demand fluctuations seem unlikely within the franchise term. Examples of activities which fulfil these conditions and which might, therefore, be suitable candidates for franchising are transport services (e.g. buses), electricity distribution, cleaning of hospitals and schools, and refuse disposal." Domberger (1986: 282).
} 
expected. Less expected and more important, perhaps, is the task of the client once the contract is signed. The contract requires London Underground's continued involvement in monitoring and enforcement for the next thirty years. It must negotiate claims for breaches of its dependencies, literally on a daily basis. It must update its growth projections at least annually. It must negotiate and agree any allowed increases in charges, which includes making judgements on the allocation of risks and responsibilities for ongoing events. It must decide whether or not to commission new works and if so of what kind. It must then embody the new works in Variations, and agree price or cost adjustments. In short, London Underground's continued supply of electricity requires its continued liaison with the Contractor. There is thus a significant ongoing relationship - including provision for adjusting the terms of the agreement over time - that constitutes an important part of what Goldberg calls an administered contract. The detailed monitoring and supervision, the detailed standards for costs and information, and the deductions for inadequate performance are not dissimilar to some regulatory arrangements.

Yet the administered contract here is not a regulatory contract in the sense of US rate of return regulation or UK RPI-X regulation. Once the contract has been bid for and agreed, prices and revenues for the specified work are fixed for thirty years, and not set on a cost-plus basis nor reviewed on request or every five years. There is no transfer of ownership of assets to SPL, no capital rate base, no unilaterally-determined approved rate of return ${ }^{56}$. There is a contractual obligation to install specified initial works, and to maintain the average age of specified groups of assets at specified time intervals, but otherwise there is no approval process (ex ante or ex post) for operating or capital costs, and normally no additional checks on capital expenditure provided that these contract obligations are met and quality of service is maintained.

Williamson (personal communication, 20 February 2002) has commented on the SPL/LUL contract as follows.

"In general, LUL and SPL seem to have thought through the project very carefully and provided a lot of 'governance structure' to help them manage the relation over time. Also, as you make clear, this is a rather special bilateral relationship between two wellinformed and qualified parties in a mature 'situation'. I conjecture that the contract and attachments run to several hundred pages. That is not the franchise bidding that Demsetz and Posner were describing.... What you tell us, I think, is that carefully crafted long-term contracting in carefully delimited circumstances can be an attractive alternative to unified ownership of both stages in both private sector and (perhaps especially) public sector programs. I have no problem with that.

I do, however, anticipate that the SPL/LUL contract will pose strain as this contract plays out if major unanticipated disturbances arise. In that event, "renegotiation" pressures will build up (especially if SPL is the disadvantaged party). I also conjecture that there will be problems as the 30-year termination date comes up and a renewal competition is conducted. But this is not to say that the current contract is worse than LUL supplying to its own needs. Moreover, I suspect that the parties have already thought about and would concede that there are problems of both kinds."

\footnotetext{
${ }^{56}$ The rates of return to debt and equity set out in the winning bidder's financial model are used as the basis for costing Variations that need additional capital, but these rates are determined by the outcome of the initial competitive tender, not by LUL, a regulator, judge, court or commission.
} 
This seems a fair appraisal, and consistent with what is set out above ${ }^{57}$.

\subsection{Long-term versus short-term contracts}

If it is possible and advantageous to provide LUL's electricity network services by a longterm contract, could these services equally have been provided by a series of short-term contracts? If so, given the advantages of the latter, why did LUL not choose them?

Short-term contracts are indeed in use elsewhere for a similar service. Two UK regional electricity companies (London Electricity Group and TXU Europe) have recently contracted out their distribution network services to a joint venture subsidiary called 24seven, on short-term contracts (five years fixed plus a one-year option to extend). 24seven provides each company with infrastructure investment planning, project management, network control, construction and maintenance, and a range of other services including dealing with calls from customers about loss of supply.

Williamson noted the advantages of recurrent short-term contracting compared to long-term contracts, but also the crucial need for parity among bidders at contract renewal. He saw two obstacles to such parity: the complexity or cost of equipment valuation, and difficulties associated with transferring specialised "human capital".

The 24seven contracts deal with the first problem by leaving ownership of the distribution system assets with the utility, not the bidder. They deal with the second problem as the LUL/SPL contract does: by specifying that the contracts are governed by TUPE regulations that provide for employees automatically to transfer to the new employer on the same terms and conditions. Moreover, "the contracts call on 24seven to prepare each year an exit plan for the two asset owners. This means there is a comprehensive plan in place that will allow the asset owner either to reabsorb their part of the 24 seven organisation or, the more likely as time goes by, to assign the contract to a competitor.",58 The outgoing contractor is required to assist the client and an incoming contractor in a transition. The contractor would normally wish to honour this obligation rather than acquire a reputation for being uncooperative.

The re-award situation has yet to be faced, but in the meantime quality standards have been improved and financial targets met. Reportedly the savings exceed those guaranteed in the contracts, which in turn beat the targets set by the regulator.

Why did LUL not adopt short-term contracts? The main disadvantage would have been the uncertainties about the future. LUL wanted to understand better its future costs and commitments, not subject itself to further uncertainties. This was particularly important with respect to staff prospects, since LUL envisaged transferring most of its Power System staff to the Contractor.

A second consideration was that LUL wished the contractor to procure equipment, not just provide service. Hence there was advantage in requiring the contractor to bear the consequences of its choice.

\footnotetext{
${ }^{57}$ On the specific issue of page length, the SPL/LUL contract itself runs to 230 pages, plus a 50 page Schedule for definitions and a further Schedule for interpretation. In total, project documentation is of the order of 2500 pages. By comparison, the Electricity Act 1989 that provided for the privatisation and regulation of the industry ran to 74 pages plus 90 pages of Schedules. The present licence for a regulated distribution business is some 50 pages long.

${ }^{58}$ Harpley (2001). For further discussion of the 24seven contracts, see Owens (2001) and Littlechild (2001).
} 
A third consideration was the higher cost of repeated transacting. The set-up costs would need to be priced into the contracts. LUL would have to cover the legal and technical costs for all the participating organisations in the winning consortia. These costs could be high - they were about $£ 15$ millions for SPL in securing the present contract ${ }^{59}$. Costs might not be so high for a shorter and more limited contract, and the one-off learning costs and due diligence over unfamiliar assets could be spread over a series of contracts, but they would still be significant ${ }^{60}$.

It is beyond the scope of this paper to evaluate whether LUL made the right choice between long-term and short-term contracts, though there is no reason at present to believe that it has made a wrong choice. Apart from explaining its reasons for its choice, the point here is that 24 seven's experience suggests that contracting out electricity network services via short-term contracts can be feasible and advantageous too, relative in this case to private sector in-house provision. ${ }^{61}$ However, short-term contracts, like long-term ones, also involve time and effort to design and monitor.

\subsection{Contracting out versus regulation}

Williamson has suggested that rate of return regulation is a form of contracting that minimises windfall gains and losses, and facilitates smooth low cost adjustment to changing circumstances. Goldberg (1976: 438) comments that "one form of cost-based pricing - rate of return regulation - appears to be at least a plausible choice. It is not obvious that any of the other imperfect flexible pricing mechanisms ... will be superior". Instead of using the bidding process to determine the revenue charge for the thirty-year duration, the contract could have embodied cost-plus and rate of return provisions, while maintaining asset ownership with LUL. Why was this not attractive to LUL? There were at least two reasons.

First, LUL wanted to know its costs with some certainty for the next thirty years. A long-term contract with a fixed price path facilitated this whereas a rate of return approach would have left this uncertain. Second, the scheme had to be judged against the Public Sector Comparator (see Appendix), and this required that the contract transfer most of the risks to the contractor. It would have been difficult to justify the scheme on this basis if LUL continued to take the risks implicit in a traditional utility regulation approach. An RPI-X regulatory approach would similarly have been unattractive to LUL if it involved the costs and uncertainty of renegotiating every five years or so.

Nor would either of these regulatory approaches have been particularly attractive to SPL. Cost-plus and rate of return arrangements would have offered inadequate scope for the exercise of its commercial judgement and management ability. It would expect these skills to yield a higher return than a low-risk low-return regulated utility business would. An RPI-X approach would also have been unattractive because of the limited scope for

\footnotetext{
${ }^{59}$ This is rather higher than figures quoted elsewhere - e.g. Pollitt (2000), citing Kerr (1998), refers to $£ 0.5$ million per bidder to prepare initial bids and $£ 3$ million final bid costs for winning hospital bid projects.

${ }^{60}$ Reducing the transactional burden of repeated short-term contracting is seen as important for the public sector in general, which is not regarded as strong at negotiating and managing commercial relationships. The PFI approach minimises the contractual interfaces in terms of numbers of contractors and time periods.

${ }^{61}$ Another UK utility has suggested that there may also be savings from specialising in the operation of distribution businesses, apart from any benefit from contracting out, so a blanket endorsement of contracting out would be premature.
} 
achieving such a higher return. There was little opportunity for additional work within the Underground. As to reducing the costs of the existing business, by the time of the contract many inefficient working practices had already been eliminated and the LUL staff had already been reduced by about a quarter.

In principle, it would have possible to privatise LUL's electricity network, and subject it to utility regulation. Would this have been more efficient than the present contract? A commentator has observed that a private owner might have found a more efficient investment program than the one specified by LUL. It might have had stronger incentives to monitor efficiently than the remaining LUL staff, especially if the latter's ability to judge compliance were to decline over time. A regulator would likely have chosen price regulation over a series of shorter periods, reducing risk to the new owner and possibly sharing efficiency gains with customers. A regulator might have been expected to take a more independent line in the event of a failure to comply, than would LUL towards its former colleagues.

These are certainly possibilities. On the other hand, SPL and 24seven would maintain that specialisation and commercial contracts with other parties are conducive to greater efficiency than are the internal procedures of a large organisation subject to regulatory constraints ${ }^{62}$. Mention should also be made of the positive effect of financing arrangements. $^{63}$ In the event, political considerations ruled out privatisation and regulation of LUL's electricity network, quite apart from the questionable policy of doing this when LUL was the only buyer for its services.

\subsection{Alternatives for LUL in entirety}

It is worth considering briefly the broader policy issue, of arrangements for LUL in its entirety rather than for its electricity network alone. London Underground Ltd was a wholly owned subsidiary of London Transport, a nationalised industry with statutory powers and duties, and answerable to the Department of the Environment, Transport and the Regions. It would have been possible to privatise LUL as a single entity and then regulate it as a utility. Successive governments rejected such an approach. The policy actually adopted has been to put out to competitive bidding the main constituent parts of the business under a

\footnotetext{
62 "In both cases [SPL/LUL and 24seven], there are gains from giving undivided management attention to a function that was hitherto considered less important or less interesting than other functions. Appropriate and modern IT systems have now been installed to deal properly with this function. Improved procurement and planning procedures have resulted. In both sets of contracts the allocation of risk is crucial, and responsibilities are spelled out in detail. For example, where force majeure is invoked, the conditions that constitute this are defined precisely. An important focus of the contractors in both cases is risk management. This is achieved by improved efficiency and by taking steps to mitigate the risk. The internal management procedures of a relatively large organisation have now been replaced by contractual obligations to an external party. These obligations are spelled out explicitly, and there are clearer financial or other consequences for each party if they are not met. This has considerably sharpened up performance." (Littlechild, 2001: 58)

${ }^{63}$ A commentator notes that the form of PFI financing is an important element in its success. Project finance by its nature is secured on the direct cashflows from the asset, and not the general corporate balance sheet of the parent company. This means that lenders have to look to the robustness of the project. This due diligence is more professional and thorough than the way that public sector projects are tested, and is a key factor in the benefits of PFI over traditional procurement. Indeed, lenders under project finance terms play a vital role in monitoring the ongoing performance of the contractor, just as much if not more than the public sector contract management team."
} 
series of PPP contracts ${ }^{64}$. The plans envisaged extending this approach from electricity to infrastructure maintenance and then to other services including telecommunications, the property assets, ticketing and security.

Maintenance of the underground railway line infrastructure has been tendered in three groupings of three to five lines each. Interestingly, this offers some prospect of the competitive alternatives in the labour market to which Peacock and Rowley attached importance, even though the prospects for competition in the product market are limited. It may also strengthen LUL's position in monitoring and costing Variations, and maintain better prospects for competition at the renewal stage, than if all the lines had been tendered together. As it happens, however, one consortium is the preferred bidder for two of the three groups of lines.

These PPP contracts are for 30 years, as with the SPL/LUL contract, but with "periodic review" provisions. ${ }^{65}$ The full implications of this are as yet unclear, but many of the factors discussed in this paper are evidently relevant. ${ }^{66}$

In parallel with the awarding of these PPP contracts, responsibility for London Transport is being transferred to the Mayor of London ${ }^{67}$. The recently elected Mayor of London and his appointed Transport Commissioner have expressed concern about the allocation of responsibilities and the operational implications thereof. They have opposed the PPP plans, including in the courts. Implementation is as yet uncertain.

Although an evaluation of the various options is beyond the scope of this paper, two points again emerge clearly. First, for good or ill, the government has in practice preferred competitive bidding schemes to privatisation plus a utility regulation approach. Second, the design and implementation of the associated contracts are likely to be matters of considerable complexity and cost.

\footnotetext{
64 “'On 20 March 1998 the Deputy Prime Minister announced that the Government would be introducing PPPs to bring stable, increased investment into London Underground. The plans involved dividing London Underground into a publicly-owned operating company responsible for delivering services to customers, and three privately owned infrastructure companies. ... Under the PPP, train and station services would continue to be planned and operated by a publicly owned, publicly accountable London Underground. London Underground would be responsible for safety on the whole of the Underground. Private companies have been invited to bid for the responsibility to maintain and upgrade the track, tunnels, signals, stations, lifts, escalators and trains under 30 year contracts to London Underground. At the end of the contracts, the assets would return to the public sector." National Audit Office (2000:17)

65 "Periodic review: A provision in the PPP contract which, every $71 \frac{1}{2}$ years, allows London Underground's payments to the Infrastructure companies to be reset to take account of changed circumstances and cost increases which an 'economic and efficient' Infrastructure company would incur." (National Audit Office, 2000: 16)

66 "London Underground is comparing these [bid and Comparator] costs over the whole 20 year contract period, and also over the first $7 \frac{1}{2}$ years. The purpose of the $7 \frac{1}{2}$ year comparison is to consider the reasonableness of bid profiles and to protect against bidders attempting to bid low to win the contract and then adjust prices upwards following the first periodic review after $7 \frac{1}{2}$ years." (National Audit Office, 2000: 7)

67 “Transport for London (TfL) is a new body, reporting to London's Mayor. It is responsible for a wide range of transport in London, primarily implementing the Mayor's integrated transport strategy. On 3 July 2000 TfL took on all of London Transport's previous responsibilities apart from London Underground. Once the [PPP] competitions are completed, London Underground will be wound up and London Underground will be transferred to TfL and the Mayor." (National Audit Office, 2000:17)
} 


\section{$5 \quad$ Conclusions}

The contract between London Underground and Seeboard Powerlink suggests that the arguments of Demsetz, Posner, Williamson and Goldberg all have merit, albeit with some qualifications.

Competitive bidding for a long-term contract has indeed been used to provide a service - electricity distribution - that is normally characterised as a natural monopoly, and so far apparently to advantage. Similar contracts have also been used for other services provided by London Underground, and to build and maintain roads and bridges, schools and prisons. This suggests that, instead of being privatised and made subject to utility regulation, the maintenance and operation of the main utility networks (including gas, electricity, telecommunications, water and rail) could all have been put out to competitive tender, and hence to the rivalry of the open market place. Demsetz and Posner were right, therefore, to draw attention to competitive bidding as an alternative to utility regulation.

Whether competitive bidding is the best option is another matter. The SPL/LUL contract, and the associated design, bidding, monitoring and Variation processes, incorporate a degree of complexity that was scarcely hinted at in the early discussions of competitive bidding. One commentator has suggested that the simplest concepts of competitive bidding are to the SPL/LUL contract what tic-tac-toe (noughts and crosses) is to chess.

The important contributions of Williamson and Goldberg were to draw attention to the nature and magnitude of the problems inherent in long-term investment under uncertainty, that need to be faced by any contract and bidding process as well as by regulation. They explored the various methods for handling these problems in terms of contracts and bidding, the limitations of these methods, and the similarities to utility regulation. Examination of the SPL/LUL contract has endorsed the importance of the factors to which Williamson and Goldberg drew attention. It has not ruled out competitive bidding, but rather shown how it is necessary for such an approach to address the problems that these latter authors identified.

While the present paper may help to reconcile the arguments put forward by the previous authors, it does not draw to a close the debate on the merits of competitive bidding and utility regulation. On the contrary, it may reopen it. Both approaches have been widely adopted in the UK and elsewhere over the last two decades, and in broad terms both have proved beneficial in terms of prices, quality of service, efficiency, innovation and so on, relative to continued public ownership of various kinds. But they are alternatives to one another. Under what circumstances is one approach preferable to the other, and under what circumstances is each approach actually chosen in practice?

Williamson (1976: 75) has already identified a number of potentially relevant factors, including costs of ascertaining customer preferences, efficacy of bidding, nature of technology, demand uncertainty, idiosyncrasy of skills, specialisation of equipment, and susceptibility of the political process under either mode. Since he wrote, there have been improvements or modifications in the techniques of both competitive bidding and utility regulation, though no doubt the underlying factors remain important. It may also be that intermediate solutions are available - for example, by enabling or encouraging regulated utilities to put out to competitive tender more of their own requirements. In all these issues, the incentives of the public or private sector client as innovator and residual monitor will be an additional relevant factor, and similarly for the incentives of the operator. Ownership 
and the nature of regulation will impact on both factors. All these issues warrant further consideration.

\section{Appendix: The treatment of risk in the SPL/LUL contract}

This Appendix explores in more detail the issue of risk, which is central to any long-term contract. It discusses how the SPL/LUL contract allocated risk between the parties and what influenced this allocation. It then discusses how each of the parties sought to manage its exposure to risk.

\subsection{The allocation of risk}

In most commercial contracts there would be a presumption that allocating each risk to the party best able to deal with it would minimise total costs and hence maximise total benefits. Although the contract took account of this, the PFI framework had an impact in respect of risk allocation.

In common parlance, a PFI contract has to "beat the Public Sector Comparator". That is, the price in the contract with the private sector provider has to be lower than the estimated cost of doing the work in the public sector, according to a financial model agreed by the Treasury ${ }^{68}$. A key feature in the comparison is the degree of inefficiency ascribed to the public sector institution in question and, more particularly, the assumed degree of cost overrun on new construction ${ }^{69}$. It is perceived that, to be successful, a proposed PFI contract has to transfer all or most of such risk to the Contractor.

The initial thinking was therefore to transfer the maximum possible amount of risk to the Contractor, rather than to consider what pattern of risk sharing would minimise total costs. For example, in order to meet increasing demand, LUL was faced with the problem of how to achieve 30 trains an hour at certain times, rather than 20. Several different technical solutions were viable. But instead of deciding which solution to adopt, and then

\footnotetext{
${ }^{68}$ The National Audit Office has emphasised that the Public Sector Comparator is not a pass-fail test, especially given the limitations of 30-year modelling, but one of a range of analyses that can inform the value for money decision. "In some past PPP transactions, the process of preparing a Comparator has been separated from the rest of the PPP procurement. ... [Government] departments should in future ensure that value for money decisions are not based on one-dimensional comparisons of single figures. Understanding the differences between the private sector and pubic sector approaches to the same output specification lies at the heart of assessing value for money. In choosing the PPP option, departments must always ensure that they understand how the private sector is delivering value for money, and why, in their judgement, it would not be possible for the public sector the achieve the same value for money." (National Audit Office, 2000: 2, at paragraphs 8-10)

69 "The preparation of the comparator needs to address the different factors which will determine whether a wholly public sector option or a PPP will give best value to the public sector over time. The most important factors are

The retained risks which, by their nature, always rest with the public sector....

The base costs of providing the services required by the public sector

The risk adjustment of the base cost figures, to reflect the probability that services will not be delivered at the cost shown in the base case projection, because of events like cost overruns or technical problems or that budgets may be maintained but at the expense of reductions in service quality."

London Underground Public-Private Partnership: Methodology for Preparing the Public Sector Comparator, pp. 1-2.
} 
putting it out to tender, LUL invited bidders themselves to solve the problem, and to take the associated risks. On this basis, the price that SPL bid for the contract as a whole covered about $£ 100$ million of investment at its own risk. This was in addition to the costs and risks of running Lots Road power station until it was shut, taking on and relocating existing staff (including moving out of a depot at Wood Lane), organising the construction joint venture, running the system for thirty years, then handing back the assets in the specified condition. In effect, the contract transferred all the design, construction and staffing risks to the Contractor.

The allocation of risks and costs was by no means fully specified in advance of the bidding process. Many reallocations emerged in the course of negotiations, and as new risks were identified. This was particularly the case after the four pre-qualifying bidders had been reduced to two, and serious discussions were held with both before best and final offers were invited. As a result of these modifications, not all the risk was left with the Contractor.

Certain risks were left with LUL, particularly those that were more clearly subject to LUL's influence. (For example, the Contractor had to supply power to meet the load specified by LUL, and took the risks associated with that, including that the chosen cable size would be adequate. But LUL took the risks of the load being different from that specified, and of the Contractor being unable to get access to the track to do electrical work as a result of breakdowns on the railway.)

Risks were assumed by LUL where it turned out less costly to do so. (For example, it was cheaper to leave on LUL's insurance the risks of flooding and rising groundwater in the tunnels, since they were a small part of LUL's business, than to require the Contractor to take out separate insurance for this.)

Where the cost of accepting 100 per cent of a particular risk was too high, this was capped. (For example, liability at Lots Road is limited to $£ 0.25$ million in relation to any single event and to $£ 3$ million in aggregate. This covers the possibility of a major plant failure such as a turbine blowing up but not beyond that level. The liquidated damages for failure to meet specified standards (see below) are also capped at a low level initially. In later years the caps are increased to reflect the fact that with better funding over time the Contractor can accept more risk.)

Other risks were shared or apportioned. (For example, there is a change of law clause dealing with the costs of any such change. If the change is specific to rail then LUL bears the costs, but if it is a general change of law then the Contractor does.)

In large part the outcome is considered to be a situation approximating the normal one where risks are placed with the party best able to handle them. Nonetheless, the need for the contract to reduce risk to LUL as far as possible, relative to the Public Sector Comparator, seems to have left greater discretion and risks to the Contractor than would otherwise have been the case. Notably, this includes how to meet LUL's Initial Works programme and its future demand for electric power.

\subsection{Protection for LUL against quality risk}

A thirty-year contract is unusually long. Both parties had reservations about the associated risks. How have the parties sought to protect themselves against the quality and price risks of such a long-term contract? 
For LUL, one quality risk is whether the performance levels have been specified correctly in the contract. Here, LUL was reasonably confident that its existing specifications would be appropriate, though it needed to extend these to deal with the contracting out of a service that had previously been provided in-house and hence had not been explicitly specified. It also had an experienced staff to do this. More serious was the question of whether the Contractor would be able and willing to perform to the specified levels. Here, the reassurances to LUL included those associated with the contracting process and those written into the contract itself, as well as certain steps taken voluntarily by the Contractor.

Among the quality assurances provided by the contracting process were the following:

(1) LUL took preliminary soundings that indicated that there was interest among the relevant potential bidders and that the proposed contract package was reasonable from their perspective. Because the interested parties had had an opportunity to comment at this preliminary stage, there was correspondingly less need to modify the contract during later negotiations;

(2) The serious bidders were experienced and reputable. They were power utility businesses with experience in rail operations, acting in association with established manufacturers;

(3) Pre-qualification procedures were a preliminary version of the final marking scheme (see next item). They were used to screen interested bidders, and four consortia pre-qualified. Each typically contained a regional electricity company or a major generator, a heavy industry manufacturer, a contractor and a financial institution. LUL felt that there was adequate competition here;

(4) The marking scheme for the tenders identified four main criteria: engineering, safety, human resources and commercial. Engineering and safety criteria were of the highest importance and had to be met. LUL was looking for railway experience here, including evidence of operational work on the railway and familiarity with access and safety training. It wanted the Contractor to do its own thinking and not just follow orders;

(5) The technical solution, including the programme of work to meet the contract specifications, was not to be forced upon the Contractor. The Contractor itself would draw it up, after considerable opportunity to do due diligence and satisfy itself as to its feasibility. As it happens, the solution proposed by the winning bidder was in fact the solution that LUL itself would have adopted if funds had been available to it. In addition, LUL's own staff, and its own technical advisers, and the technical advisers to the banks, had all assessed the solution proposed by the Contractor, and found it acceptable;

(6) The transfer of over 300 staff from LUL would enhance the technical ability of the Contractor. LUL would keep about 30 staff for the purpose of monitoring and enforcing performance under the contract. All these staff were trained for their 
respective purposes. They knew the system and had carried out essentially the same functions internally under previous arrangements.

Contractual provisions to reassure LUL as to quality included the following:

(1) The Ultimate Reversionary Requirements specify that at the end of the contract, i.e. after 30 years, the average remaining life of each category of asset must be at least 50 per cent of the specified typical average life of that category of asset. There are also Intermediary Reversionary Requirements that apply after each five years ${ }^{70}$. Penalties for failing to meet these Requirements could reduce the Contractor's income from availability charges by up to 40 per cent. LUL can require an independent report, at the Contractor's expense, on whether or not the assets and the system comply with the Intermediary Requirements;

(2) A substantial programme of Initial Works, agreed as part of the contract, has to be completed by the specified completion dates, otherwise Deficiency Points and Liquidated Damages (see below) begin to apply;

(3) The contract makes provision for the Contractor to pay Liquidated Damages to LUL for failure to supply electricity. Liquidated damages are required to be a genuine pre-estimate of a party's loss as a result of failure to meet the contract, and hence are intended to compensate LUL for any such failure of supply. These liquidated damages had been previously and conscientiously estimated in great detail, station by station, hour by hour, with assumptions about the loss of revenue depending on the number of passengers likely to be lost or diverted ${ }^{71}$. They range from $£ 50$ per hour to $£ 100,000$ per hour;

(4) The availability charge payment to the Contractor is reduced proportionately to the extent that plant is out of service when it should be available. This includes transformers, compressed air facilities, central and local emergency supply facilities, and so on;

(5) The contract embodies a Deficiency Points regime with provision for termination. Deficiency points are incurred for breaches of thresholds in 36 categories covering a wide range of performance, including operational and equipment failure, breaches of the safety regime, inability to maintain quality accreditation and failure to submit reports on time. A running total is kept. If the Contractor exceeds a specified limit it gets a warning. LUL has the right to terminate the contract after three such warnings. In practice the deficiency points regime has proved more demanding on

\footnotetext{
${ }^{70}$ The first such Requirement specifies that after five years the average asset life must be at least 35 per cent rather than 50 per cent in each category. This does not imply a more lax approach to quality at the beginning of the contract. Indeed, among all the contract conditions, the Intermediary Requirements were considered most favourable to LUL. Rather, the specification was intended to give the Contractor greater scope to plan and smooth the investment programme. There are significant constraints relating to skills, access, plant availability and impact on the railway. These necessitate more flexibility than in an ordinary electricity distribution network.

${ }^{71}$ The estimates had previously been compiled as part of LUL's investment case to the Government, and are embodied in a thick book appended to the contract.
} 
SPL than the liquidated damages provisions. Moreover, the financial lenders to SPL take this aspect particularly seriously, and regard it as a key measure of efficiency;

(6) The Contractor is required to comply with an Operation and Maintenance Regime and an Upgrades and Renewals Regime. These Regimes are like Codes of Practice, they specify the manner in which the contractor will look after the network. If there is a breach of a Regime LUL may issue a Corrective Action Request with which the Contractor is required to comply. Changes to the Regimes can only be made in accordance with a specified procedure. Under the terms of a Contract Management Schedule, the Contractor is required to obtain LUL's approval before deploying certain new or altered works;

(7) There are extensive provisions regarding information, planning, audit and reporting. LUL and authorised third parties are entitled to inspect the system and the IT systems, with and without prior warning, to ascertain whether the Contractor is complying with its obligations. The Contract Management Schedule requires the Contractor to supply various reports, including a Four Weekly Report that reviews performance $^{72}$. The Contractor is required to provide LUL with its Annual Operating Plan and its Five Yearly Operating Plan, to accept any reasonable changes requested by LUL, and to comply with these plans. The Contractor has to test the assets periodically according to a specified regime, and report to LUL, which is entitled to be present at the testing. The Contractor must promptly repair, renew or replace any assets not operating in accordance with the Performance Specification. The Contractor must keep an up-to-date Asset Register and Contract Register, to which LUL has access, and must provide LUL with an annual copy of these, identifying all changes that have occurred during the year;

(8) There is some provision for defined consequential losses, such as reasonable costs of contractors to LUL and in relation to death or injury resulting from the negligence of the Contractor;

(9) The Bidder's Financial Model, originally developed by each bidder to enable it to calculate its bid, also gave LUL an understanding of how the bid price related to the elements of cost and requirements in the contract. In particular, it enabled LUL to satisfy itself that all its requirements had been priced in, that there were no missed items, that the bidder envisaged spending enough in future years, etc. ${ }^{73}$

Two other developments and considerations helped to assure LUL:

\footnotetext{
72 This is based on the review process that LUL had previously established to monitor its own performance. It is designed to cover a situation where things are not going well, and where there is initial uncertainty, but can be relaxed if circumstances justify this. The Report for the four weeks ending 3 March 2001 is presumably not atypical. It has some 100 pages of detailed reporting of such things as failures to supply, system nondelivery ratios, liquidated damages and deficiency points, graphical plots of faults and failures, plant out of service, maintenance completed, audit progress, safety and environmental implementation plans, remedial actions, renewals and upgrades progress, incident investigations, variations, works with potential to affect reliability, assets installed and disposed, disruption claims, disputes and problems, financial and fuel statistics, metering and liability costs.

${ }^{73}$ Lodging of the financial model was a condition precedent of the contract, and the model is used in calculating allowed costs of Variations, as discussed below.
} 
(1) SPL's participation is on a highly leveraged basis. The banks that lent to SPL required that it build up a year's turnover and keep this in the form of reserves. This is an assurance to LUL as well as to the banks. The willingness of the banks to lend to SPL in the first place, and continuing evidence that they are content with the situation, provides some further assurance to LUL;

(2) In designing its own works to ensure compliance with the performance specification, SPL decided that it would seek levels of system security not less than those applied by LUL in the past. It would use existing LUL standards until it developed its own standards, and in the absence of applicable LUL standards would use British Standards or recognised International Standards. ${ }^{74}$

All these conditions were designed or helped to provide LUL with assurance that the Contractor would perform as intended with respect to quality of service in the immediate and more distant future.

\subsection{Protection for LUL against price risk}

A second main source of risk for LUL concerned price. Would LUL be paying too much for the contracted out services, or be perceived as doing so at some time in the future? Would the Contractor be perceived as making too much profit from the contract? LUL had the following sources of assurance:

(1) The terms offered by the Contractor had been the result of a vigorous tendering and bidding process involving several well-qualified and interested consortia, and LUL regarded this process as competitive;

(2) The Treasury had tested the proposed terms against its Public Sector Comparator, which estimated the cost of LUL itself carrying out the work, and concluded that the terms offered were better;

(3) LUL's own calculations, independent of the Treasury's calculations and not shared with LUL's engineering team so as not to bias engineering decisions, showed that the final contract terms offered worthwhile savings to LUL;

(4) LUL was advised by its technical consultants that there were no dramatic technical advances in the offing that were likely to reduce the Contractor's costs significantly in future;

(5) Because there was some prospect of a future reduction in the cost of electricity itself following the opening of the competitive market, and other prospective advantages from being able to choose a supplier, LUL withdrew the provision of electricity from the contract and retained this function for itself. It required the Contractor to pass through the cost of fuel purchased by LUL and to provide assistance and advice on purchasing;

\footnotetext{
${ }^{74}$ Buchanan and Hardy (1999: 9)
} 
(6) Because there was some prospect of future income from sale of surplus generation and from charges to third parties for use of LUL's system, the contract provided for LUL to share in these revenues, and in any commercial exploitation of the cable ducts (e.g. for telecommunications).

\subsection{Protection for LUL against opportunism}

Many economists have stressed the dangers of one party locking itself into a monopoly relationship that could render it vulnerable to opportunistic price increases by the other party in future. Would LUL be vulnerable in this way? Not on the services covered by the contract. For the next thirty years these were to be provided at a fixed price basis established by the bid. But LUL could be vulnerable to opportunistic overstatements of cost in certain other respects, and the contract seeks to prevent this.

First, some aspects of the Specification require an ongoing commitment from LUL in order to allow the Contractor to perform. The contract contains a schedule listing these so-called LUL Dependencies. For example LUL must provide specified access to the track. If LUL does not do so, the Contractor can claim for Disruption Costs.

To minimise opportunism here, the contract provides that Disruption Costs are payable only according to a clearly defined mechanism. Claims are required within a certain time and with specified detail. The Contractor must keep contemporary records, which LUL may inspect, and LUL may instruct the Contractor to keep further records. The Contractor has a duty to notify LUL of any circumstances that might lead to a claim for Disruption Costs and a duty to mitigate the LUL's exposure (e.g. by deploying staff elsewhere rather than leaving them idle).

Second, the bids and contract were based on a future load specified by LUL, reflecting its estimate of future rail output and the pattern of future train running. If this estimate changes, LUL has to compensate the Contractor for its additional costs.

Because of the difficulty of estimating future demand, the estimates were initially made for 5 years ahead rather than 30 years. For each item of equipment, the capacity, the load on the system and the spare capacity, at the time of handing over the system, were all jointly agreed with the Contractor. Each year, LUL has to provide the Contractor with its best estimate of any changes to its future requirements in each of the next five years. "It will provide as much detail as is reasonably practicable and will indicate the degree of certainty attached to each part of the estimate." In the light of this the Contractor has to provide an Annual Operating Plan and a Five Yearly Operating Plan. A Minor Load Change, which can be accommodated within the defined capacity, will not normally give rise to additional costs. A Major Load Change, which cannot be so accommodated, is treated as a Variation (see below). ${ }^{75}$

Third, it was envisaged that LUL would subsequently wish to commission various new works beyond those covered by the original contract. The contract provides that LUL may request a Variation in the contract to deal with changed circumstances or revised plans on the part of LUL. These Variations are typically rather small individually, but in

\footnotetext{
${ }^{75}$ The Contractor may be requested to provide information in support of any claimed Major Variation, and "the Contractor shall provide such co-operation and information as LUL may reasonably require to establish whether any proposed Major load Change may be implemented ... in any other way as a Minor Load Change."
} 
aggregate are substantial relative to the initial investment in the original contract. ${ }^{76}$ One Variation is exceptionally large. ${ }^{77}$ It is therefore necessary to protect the interests of both parties by prescribing rules for implementing Variations.

On the one hand, to protect the lenders, the Contractor is not obliged to implement the Variation if it would unduly increase risk $^{78}$, or if the Contractor is unable to raise sufficient additional finance. And if the Variation increases the Contractor's costs or risks (such as the risk of having to pay greater liquidated damages), the Contractor is entitled to a price adjustment. This is calibrated "to ensure that the Contractor is financially no better and no worse off than if it had not been required to implement the Variation".

On the other hand, to protect LUL, the Contractor may not refuse to implement a Variation on the ground that it is unable to raise sufficient additional finance unless a number of avenues have been explored without success. LUL has the opportunity to make advance payments and the right to attend meetings with lenders to discuss the reasons for refusal to provide such additional finance. If the Contractor argues that additional equity is necessary to raise additional finance and that this requires a higher internal rate of return than provided for in the contract, then LUL may request the Contractor to get additional quotes from lending institutions, and may obtain the funding itself if the Contractor chooses not to invest.

LUL could be particularly vulnerable to opportunistic cost inflation with respect to Variations. The contract therefore seeks to strengthen LUL's position. The contract requires that "The Contractor shall comply with the Cost Optimisation Principles and.... shall take all reasonable efforts to minimise the adverse and maximise the favourable financial impact on LUL of any Variation". The Cost Optimisation Principles mean that "the cost of assets and services will be assessed on the basis of the lowest reasonable whole life costs" and work is "to be performed in accordance with Good Industry Practice". The Contractor has to take reasonable steps to demonstrate such lowest costs, including by affording LUL access to detailed information supporting these costs. LUL has the "right to require the Contractor to carry out competitive tendering if the Contractor is unable to demonstrate to the reasonable satisfaction of the Contract Manager, lowest reasonable

\footnotetext{
76 The contract provided for initial investment of about $£ 100$ million and a total investment of just over $£ 250$ million. To date nearly 200 Variations have been discussed, amounting to a further $£ 100$ million. About 6 of these Variations have been associated with Major Load Changes. Most of these Variations have been for some thousands of pounds, at most $£ 2-3$ million. There can also be negative Variations - for example the initial obligation to provide emergency supplies to radios was removed, which would have saved about $£ 19$ million. However, to minimise the cost of running the Contractor's Financial Model (see below) necessary to cost the change, this negative Variation was combined with the harmonics Variation (see next footnote).

There is a limit to the permitted extent of downsizing of the contract, as is reportedly not atypical in long-term facilities management contracts.

${ }^{77}$ The Variation to provide for harmonic filtering and voltage correction equipment has a value of nearly $£ 60$ million (half capital expenditure and half operating costs). This reflected the cost of new and more rigorous control procedures and equipment to meet the requirements of the local Electricity Area Board. This item was left out of the initial contract because these requirements were unclear at the time.

${ }^{78}$ The Contractor is not obliged to implement any Variation where "the Incremental Risk is greater than an average of 10 percent and the Risk Protections do not mitigate this to below 10 percent". Moreover, "in no circumstances should the amount of the Price Adjustment be the Principle Risk Protection". Sufficient steps have to be taken actually to mitigate the risk.
} 
whole life costs." Some 14 categories of reasonable costs are specified. The ways in which the Contractor shall comply with this obligation are spelled out in some detail. ${ }^{79}$

The calculation of such price adjustment as will make the Contractor no better and no worse off is also specified in detail. The Contractor's Financial Model that was the basis of the original bid price is revised to include the price adjustment and the anticipated changes in costs as a result of the Variation. The outcome must then maintain the criteria in the initial Model. These include specified internal rates of return to debtholders and shareholders, a specified net present value at a specified real discount rate, and residual cash balances and reserves as at the starting date. LUL can choose the profile of the price adjustment. ${ }^{80}$ If the Variation is solely for the supply of any item set out in a certain schedule, LUL may elect a Fixed Price Variation based on the pre-specified unit rates in that schedule.

The issue of vulnerability to opportunism is all the greater because the contract grants the Contractor exclusive rights to operate, maintain, renew and upgrade the electricity distribution system and the SCADA systems. The Contractor has the right to perform both the capital works and the operation and maintenance associated with any Variation. The purpose of this exclusivity clause is not to protect the Contractor. ${ }^{81}$ LUL inserted it in order to avoid disputes about responsibility: if there is no other operator on the system then the Contractor can be held fully responsible for actions and outcomes other than those attributable to LUL. However, to avoid LUL being held hostage by the Contractor, if the Contractor has failed to comply with the Cost Optimisation Principles, or to follow the specified procedures for assisting LUL, then LUL may offer such works to a third party. LUL may require the Contractor to provide services to the third party and allow access to the system and assets to carry out work, and there is provision for the Contractor subsequently to adopt the third party works.

LUL has been very rigorous in costing Variations to the contract. For example, as part of its demonstration that cost is optimised, SPL has to show that its proposed price is "about market". To do this on the harmonics Variation, SPL required ABB (the consortium member that would expect to get this work) to plot its price over the last 20 jobs that it secured to show that its price quoted for this job came under the general level of the price it quoted for those other jobs ${ }^{82}$. With increasing experience, there is now an agreed checklist of what LUL would expect to see under the Cost Optimisation Principle.

\footnotetext{
${ }^{79}$ In particular, the Contractor is required to a) suggest any alternatives to LUL's requirements that would achieve the same objective more cost effectively, b) set out the manner of implementation that would minimise the incremental risk and disruption, c) advise LUL of any new technology that materially alters the method by which the Contractor will perform the Variation and any impact that the new technology would have, d) take all reasonable efforts to plan its expenditure to meet this Variation so as to minimise the costs of any possible future Variations that LUL has said are in contemplation, and e) optimise the financing, timing and tax implications.

${ }^{80}$ Including whether to spread it over the remaining life of the Contract, or to make a single payment, or a series of payments to reflect the costs in each period.

${ }^{81}$ In contracts where individual bill items are specified such exclusivity protects the Contractor against "cherry picking" whereby the client can buy elsewhere on high margin items and force the contractor to accept quantity increases on low margin (or negative margin) items. However, LUL did not mandate such specification of bill items in the present contract, with the exception of one area where LUL could not specify its requirements at the time.

${ }^{82}$ LUL also took independent advice on this matter, and would expect to do so in future for major Variations.
} 
LUL had another concern about "lock-in". Would it be able to benefit from new technology in future, and would the contract have an adverse effect on the development of that technology? For example, several manufacturers used to develop new products for LUL (e.g. fireproof materials) but if they believed that the manufacturer member of the Contractor's consortium would automatically get all the work in future by virtue of the contract, why should they bother to develop such products? The contract therefore requires the Contractor to keep LUL informed of the existence and impact of any new technology and to choose the method that minimises costs. SPL profits from such general awareness. LUL is not at significant risk on failure to adopt innovations on existing work, given the advice to it about no major innovations being imminent, and it can profit from such innovation on the new work it commissions. In the event, there has been no problem with other manufacturers to date, and in fact SPL has bought from one innovating manufacturer outside the Consortium that had previously expressed fears.

\subsection{Protection for SPL against quality and price risks}

SPL was as concerned as LUL about the risks to which it was exposing itself. Could it be confident that it could deliver the promised service for the price it had quoted, a price that was irrevocable for thirty years? If costs did turn out to be higher than expected, SPL could hope to get the price right on subsequent work, although there was a tough process of justification for Variations (see above). However, the initially contracted work was so significant that the terms needed to be right in the first place ${ }^{83}$.

The first priority for SPL was to satisfy itself that it was dealing with a manageable task. SPL therefore carried out a full due diligence examination of the state of LUL's assets, and concluded that this was essentially a situation with which it was familiar. Where the assets were initially inadequate it obtained a derogation from the requirements. No unsettling changes in policy with respect to safety were envisaged ${ }^{84}$.

\footnotetext{
${ }^{83}$ In a normal commercial context, if the situation became untenable for one or other party, some renegotiation could occur. However, this would be difficult in the political context, and given that the basis for the PFI contract was the transference of risk to the bidder.

${ }^{84}$ Buchanan and Hardy (1999: 6-7) summarise the situation as follows. "This contract differs from most previous UK PFI schemes in that the extent of the infrastructure being operated by the Contractor is much greater than the new capital works being undertaken initially. Consequently the extent of risk being accepted by SPL is heavily weighted by the adequacy and condition of these existing assets.

During the initial bidding stage, SPL placed heavy reliance upon data provided by LUL, with only a few sample on-site checks possible in the time available. SPL was helped by having within its partnership staff with knowledge of the LUL system as a result of previous and current contracts [between LUL and ABB and Balfour Beatty]. During the post-bid negotiation stage however it was necessary to confirm the initial assumptions with more detailed checks... The conclusions which SPL arrived at as a result of these investigations were:

The distribution system was generally of an age and condition comparable with that of a typical UK REC. There were a few specific areas of the distribution system which would not immediately meet the requirements of the Performance Specification set out in the contract.

The security criteria used by LUL were in line with good practice for a passenger-carrying underground railway, and complied with the requirements of the LUL Railway Safety Case....

The first of these conclusions enabled SPL, by drawing upon the expertise of SEEBOARD, to make a reasonable assessment of the risks inherent in operating the distribution system, and to establish a renewals programme on a realistic basis. The second was initially reflected in a number of qualifications to the SPL position. During the period of contract negotiation these qualifications were either covered by modifications to the contract terms, or translated into Derogations. The third gave confidence to the investors, and enabled
} 
Once SPL had satisfied itself that it could handle the business in normal circumstances, the next concern was to reduce to a manageable level the risk of unforeseen eventualities. The contract reduced these by allocating to LUL those risks that it was best placed to deal with, such as changes in load on the system, and by capping other risks, as discussed above. In addition, SPL was able to lay off other risks with insurance companies (for example, risks of switchgear damaged by water, or of catastrophic plant failure).

In some contracts there might be a worry about a client's credit rating. Here there was a worry about a "New York" scenario, in which LUL was unable or unwilling to pay its bills because of a change in political circumstances in London. (This was not a negligible concern, as the main text indicates.) This was dealt with by a change of status clause, allowing the Contractor to terminate the contract if LUL was dissolved or wound up, or if there was a change in law rendering the Contractor's performance illegal or impossible, or if LUL breached its payment obligations. ${ }^{85}$

\section{$7 \quad$ References}

Armstrong, M, S. Cowan and J. Vickers (1994) Regulatory Reform: Economic Analysis and British Experience, The MIT Press, Cambridge, Mass., and London, England.

Averch, H. and L. Johnson (1962) "The Firm under Regulatory Constraint", American Economic Review, 52: 1052-69.

Baldwin, R. and M. Cave (1999) Understanding Regulation: Theory, Strategy and Practice, Oxford University Press, Oxford.

Beesley, M.E. (1992, 1997) Privatization, Regulation and Deregulation, Routledge in association with the Institute of Economic Affairs (two editions), London.

Better Regulation Task Force (2001) Economic Regulators, July, London.

Brealey, R. A., I.A. Cooper and M.A. Habib (1997) "Investment Appraisal in the Public Sector", Oxford Review of Economic Policy, 13(4): 12-28.

SPL to base its operating, maintenance and planning policies on an assumption that LUL's safety and security approach would be continued. This in turn gave assurance to LUL."

${ }^{85}$ With regard to the valuation and magnitude of political and regulatory risks, the change of status clause mitigated this particular political risk. As regards other risks, regulatory and otherwise, it is increasingly common in project management contracts to set up a risk register to identify the nature, likelihood and consequences of all possible risks and to mitigate them where possible. For the most substantial projects Monte Carlo simulation is used to model the aggregate effect of these risks. A risk allowance would then be priced into a bid to cover a proportion of these outcomes - say, 50 per cent in a situation where the contractor was familiar with the work, or up to, say, 95 per cent where there was unknown equipment and high risk of delay. This might result in an addition to the contract of some 5 to 10 per cent of the contract value. The precise amount would depend on all the commercial circumstances. The contractor will either benefit or lose depending on how far the risks actually materialise, but overpricing this and other risks could make its bid uncompetitive. Risk is one of the 14 categories of cost identified in the contract with respect to the costing of Variations. SPL's practice in pricing Variations is consistent with the policy just summarised. A Monte Carlo simulation was used for the harmonics Variation. 
Breyer, S. (1982) Regulation and its Reform, Harvard University Press, Cambridge, Mass., and London, England.

Buchanan, I.D. and B.J. Hardy (1999) "Engineering aspects of the London Underground Ltd Private Finance Initiative Power Project", paper presented to Institution of Electrical Engineers, Savoy Place, London, 16 February.

Chadwick, E. (1859), "Results of Different Principles of Legislation and Administration in Europe; of Competition for the Field, as compared with the Competition within the Field of Service", Journal of the Royal Statistical Society, 22: 381.

Demsetz, H. (1968) "Why Regulate Utilities?" Journal of Law and Economics, 11, April: 55-66.

Demsetz, H. (1971) "On the Regulation of Industry: a Reply", Journal of Political Economy, 79, March/April: 356-63.

Domberger, S. (1986) "Economic Regulation through Franchise Contracts", in Kay, Mayer and Thompson (1986: 269-83).

Foster, C.D. (1992), Privatization, Public Ownership and the Regulation of Natural Monopoly, Blackwell, Oxford UK and Cambridge USA.

Goldberg, V.P. (1976), "Regulation and Administered Contracts", The Bell Journal of Economics, 7 (2) Autumn: 426-48. Reprinted in Williamson and Masten (1999: 438-60).

Goldberg, V.P. and J.R. Erickson (1987) "Quantity and Price Adjustment in Long-term Contracts: a Case Study of Petroleum Coke”, Journal of Law and Economics, XXX (3), October: 369-98. Reprinted in Williamson and Masten (1999: 321-50).

Grout, P .A. (1997) "The Economics of the Private Finance Initiative", Oxford Review of Economic Policy, 13(4): 53-66.

Harpley, R. (2001) "Management of Essential Infrastructure: a Socially Acceptable Model for Utility Asset Ownership and Operation Separation", 24seven, March.

Hartley, K. and M. Huby (1986) "Contracting out Policy: Theory and Evidence", in Kay, Mayer and Thompson (1986: 284-96).

H.M. Treasury (1993) Breaking New Ground: The Private Finance Initiative, HMSO, London.

Jackson, T. (1999) “Towards Enduring Regulation”, The Utilities Journal, May: 30-2.

Joskow, P.L. (1985) "Vertical Integration and Long-term Contracts: the Case of Coalburning Electric Generating Plants”, Journal of Law, Economics, and Organization, 1(1) Fall: 33-80. 
Joskow, P.L. (1987) "Contract Duration and Relationship-specific Investments: Empirical Evidence from Coal Markets", American Economic Review, 77 (1) March: 168-85. Reprinted in Williamson and Masten (1999: 281-98).

Joskow, P.L. (2000) "Deregulation and Regulatory Reform in the U.S. Electric Power Sector," in Deregulation of Network Industries: The Next Steps (S. Peltzman and Clifford Winston, eds.), Brookings Press, 2000.

Kay, J., C. Mayer and D. Thompson (eds.) (1986) Privatisation and Regulation - the UK Experience, The Clarendon Press, Oxford.

Kerr, D. (1988) “The PFI Miracle”, Capital and Class, 64, Spring: 17-28.

Littlechild, S.C. (1984) Regulation of British Telecommunications' Profitability, Department of Industry, London.

Littlechild, S.C. (2001) "Contracting out distribution services: addressing the concerns", Power UK, 87, May: 55-61.

National Audit Office (1999) Examining the value for money of deals under the Private Finance Initiative, HC 476, Session 1997-98, London.

National Audit Office (2000) The financial analysis for the London Underground Public Private Partnerships, HC 54, Session 2000-2001, 15 December, The Stationery Office Limited, London.

National Audit Office (2001) Managing the relationship to secure a successful partnership in PFI projects, HC 375, Session 2001-2002, 29 November, The Stationery Office Limited, London. http://www.nao.gov.uk/publications/nao_reports/01-02/0102375.pdf

Newbery, D.M. (1999) Privatization, Restructuring, and Regulation of Network Utilities, The MIT Press, Cambridge, Mass., and London, England.

Ofgem (2002) Review of domestic gas and electricity competition and supply price regulation: conclusions and final proposals, London, 16 February, at http:/www.ofgem.gov.uk/projects/pricereg_index.html

Oftel (2002) Consultation on Oftel's review of the fixed telephone market, London, 31 January, at http:/www.oftel.gsi.gov.uk

Owens, D. (2001) "The FT Interview with David Owens (chief executive of 24seven)", Power $U K_{2}$ 84, February: 25-8.

Peacock, A.T. and C.K. Rowley (1972) "Welfare Economics and the Public Regulation of Natural Monopoly", Journal of Public Economics, 1: 227-44.

Peltzman, S. and C. Winston (eds) (2000) Deregulation of Network Industries - What's Next? AEI-Brookings Joint Center for Regulatory Studies, Washington, D.C. 
Pollitt, M.G. (2000) "The Declining Role of the State in Infrastructure Investments in the UK", in Tsui, Berg and Pollitt (2000: 142-77) (formerly DAE Working Paper 0001, University of Cambridge, February 2000).

Posner, R.A. (1972) "The Appropriate Scope of Regulation in the Cable Television Industry", The Bell Journal of Economics and Management Science, 3 (1): 98-129.

Schmalensee, R. (1979) The Control of Natural Monopolies, D C Heath \& Co, Lexington, Mass.

Stigler G.J. (1968) The Organisation of Industry, University of Chicago Press, Chicago.

Stigler G.J. (1974) "Free Riders and Collective Action: An Appendix to Theories of Economic Regulation”, The Bell Journal of Economics and Management Science, 5 (2), Autumn: 359-65.

Telser, L.G. (1969) "On the Regulation of Industry: a Note”, Journal of Political Economy, 77, November/December: 937-52.

Telser, L.G. (1971) "On the Regulation of Industry: Rejoinder", Journal of Political Economy, 79, March/April: 364-5.

Tsui, M.S., S.V. Berg and M.G. Pollitt (eds) (2000), Private Initiatives in Infrastructure: Priorities, Incentives and Performance, Institute of Developing Economies, Tokyo (also forthcoming from Edward Elgar Publishing Ltd, Cheltenham, 2002).

Vickers, J. and G. Yarrow (1985) Privatization and the Natural Monopolies, Public Policy Centre, London.

Vickers, J. and G. Yarrow (1988) Privatization: An Economic Analysis, The MIT Press, Cambridge, Mass., and London, England.

Williamson, O.E. (1976) "Franchise Bidding for Natural Monopolies - in General and with Respect to CATV", The Bell Journal of Economics, 7 (1), Spring: 73-104. Reprinted in Williamson and Masten (1999: 406-37).

Williamson, O.E., and S.E. Masten (eds.) (1999) The Economics of Transaction Costs, Cheltenham, Edward Elgar Publishing Ltd, UK and Northampton, MA.

Zupan, M.A. (1989a) "The Efficacy of Franchise Bidding Schemes in the Case of Cable Television: Some Systematic Evidence", Journal of Law and Economics, XXXII, October: 401-56.

Zupan, M.A. (1989b) "Cable franchise renewals: do incumbent firms behave opportunistically?” RAND Journal of Economics, 20 (4), Winter: 473-82. 